\title{
Effects of Kinematic Constraints on Teleseismic Finite-Source Rupture Inversions: Great Peruvian Earthquakes of 23 June 2001 and 15 August 2007
}

\author{
by Thorne Lay, Charles J. Ammon, Alexander R. Hutko, and Hiroo Kanamori
}

\begin{abstract}
Two great underthrusting earthquakes that occurred along the coast of Peru in 2001 and 2007 involve spatiotemporal slip distributions that differ from the predominantly unilateral or bilateral rupture expansion of many great events. Commonly used finite-source rupture model parameterizations, with specified rupture velocity and/or short duration of slip at each grid point applied to the seismic data for these two events, lead to incorrect slip-distributions or inaccurate estimation of rupture velocities as a result of intrinsic kinematic constraints imposed on the model slip distributions. Guided by large aperture array back projections of teleseismic broadband $P$-wave signals that image slip locations without imposing a priori kinematic constraints on the rupture process, we exploit the availability of large global broadband body and surface wave data sets to consider the effects of varying the kinematic constraints in teleseismic finite-source waveform inversions. By allowing longer than usual rupture durations at each point on the fault using a flexible subfault source-time function parameterization, we find that the anomalous attributes of the 2001 and 2007 Peru earthquake ruptures are readily recognized and accounted for by compound rupture models. The great 23 June $2001\left(M_{\mathrm{w}} 8.4\right)$ earthquake involved an initial modestsize event that appears to have triggered a much larger secondary event about $120 \mathrm{~km}$ away that developed an overall slip distribution with significant slip located back along the megathrust in the vicinity of the initial rupture. The great 15 August 2007 $\left(M_{\mathrm{w}} 8.0\right)$ earthquake was also a composite event, with a modest size initial rupture followed by a 60 -sec delayed larger rupture that initiated $\sim 50-60 \mathrm{~km}$ away and spread up-dip and bilaterally. When back projections indicate greater rupture complexity than captured in a simple slip-pulse-type rupture model, one should allow for possible long-subfault slip-duration or composite triggered sequences, and not overly constrain the earthquake slip distribution.
\end{abstract}

Online Material: Figures of waveform fits and animations of back projections, accumulating slip, and moment-rate history.

\section{Introduction}

Seismological estimation of the space-time distribution of slip during a large earthquake is important for postearthquake emergency response, tsunami-warning systems, tectonic interpretations, and advancing understanding of fault frictional properties and rupture processes. Perhaps the most robust finite-source models are now estimated by parallel or simultaneous inversions of seismic, geodetic (GPS and/or InSAR), and tsunami observations (e.g., Salichon et al., 2003; Pritchard et al., 2007; Konca et al., 2007, 2008; Biggs et al., 2009; Sladen et al., 2010); however, rapid finite-source inversions, performed within minutes after an event (e.g., Ji and Zeng, 2007; Yagi, 2007; Yamanaka, 2007), are still based primarily on seismic observations because numerous data become available as soon as the body and surface waves propagate to global broadband stations and the recorded ground motions are telemetered to data centers. Rapid estimation of the slip distribution for a large earthquake is valuable for identifying the fault, assessing the potential for tsunamigenesis, and guiding emergency response activities to where damaging shaking may have been strongest. Ensuring accurate estimation of the slip distribution for large events using just seismic observations remains important. 
Rapid seismic inversions that use globally distributed teleseismic observations typically involve prescribed faulting geometries, often based on quickly performed point-source moment tensor inversions (e.g., Ekström, 2009), or pretabulated megathrust fault geometries for large interplate thrust events (Hayes and Wald, 2009), along with assumed rupture velocities and fault dimensions that may be based on early aftershock locations or initial estimates of the seismic moment. The fault model is usually parameterized to have a rupture front that spreads over a grid of point-source subfaults, with a specified rupture velocity (or range of velocities) defining which subfaults have been activated and a subfault source-time function parameterization defining what portions of the rupture model are slipping, at any given instant. Teleseismic body waves provide the primary sensitivity to details of the space-time slip distribution; these signals intrinsically provide a very limited sampling of the full range of seismic wave apparent velocities and at most a few seconds of differential time variations with azimuth, so the finite-source inversions commonly require stabilizing constraints imposed on the rupture kinematics and/or smoothness of the slip distribution. Typically, finite-source models fit the observed waveforms very well due to the large number of parameters: the suite of subfaults with different Green's functions, relative timing, seismic moments, and time functions activated at any instance of rupture provide many degrees of freedom to fit the data. By minimizing waveform misfit, viable finite-slip models are readily obtained, but the models retain a strong dependence on specified kinematic parameters. Surface waves extend the range of seismic wave apparent velocities and provide useful constraints on overall rupture directivity and seismic moment, but even joint body and surface wave inversions can have strong dependence on the assumed rupture velocity; simple waveform misfit criteria may not provide strong constraints for all but the very greatest earthquakes, which may produce tremendous seismic wave directivity effects (e.g., Ammon et al., 2005).

Seismic finite-source inversion methods differ significantly in the types of kinematic constraints that are imposed; they range from slip-pulse-type models that have the intuitively appealing characteristic of a regularly expanding dislocation front spreading over the fault surface from the hypocenter with spatially variable amount of slip concentrated within a short time after the rupture front arrives (e.g., Hartzell and Heaton, 1983; Ji et al., 2002), to models in which, once activated, subfaults can rupture repeatedly throughout the entire duration of faulting (e.g., Das and Kostrov, 1990; Robinson et al., 2006). These different representations have long lineages in seismic source theory tracing back to propagating dislocation rupture models (e.g., Knopoff and Gilbert, 1959; Haskell, 1964) and early crack models (e.g., Eshelby, 1957; Savage, 1966); there remains significant debate over the most appropriate physical representation of faulting. Nonetheless, it is clear that for the early finitesource rupture models based on sparse, band-limited teleseis- mic data, the information content of typical data sets was limited; some form of regularization of the inversion for the many source parameters in a finite-source model was needed. Thus, imposing strong kinematic constraints was defensible, even though the resulting models were known to have explicit dependence on the assumed parameters.

While the intrinsic space-time resolution limitations of teleseismic signals remain unchanged, and there are many issues associated with use of simplified (plane-layered) Green's functions for wave propagation effects (e.g., Okamoto and Takenaka, 2009), much larger and higher quality broadband data sets are rapidly available today. This raises the possibility of resolving differences between source models derived under propagating slip-pulse versus crack model parameterizations. This possibility is reinforced by the recent development of large network back-projection imaging of ruptures (e.g., Ishii et al., 2005; Krüger and Ohrnberger, 2005; Walker and Shearer, 2009; Xu et al., 2009), by which some aspects of the slip distribution can be resolved with minimal kinematic constraints on the space-time evolution of the rupture. We consider the fundamental problem of inversion of teleseismic waves for finite-source models for two great earthquakes in Peru for which there are extensive seismic and geodetic data sets and for which back projections of large network data sets suggest complex slip histories not captured by routine seismic finite-source inversions.

\section{1 and 2007 Peru Earthquakes}

The subduction zone along southern Peru has experienced two great underthrusting earthquakes during the past decade; the 23 June 2001 Camaná earthquake $\left(16.26^{\circ} \mathrm{S}\right.$, $73.64^{\circ} \mathrm{W}, 20: 33: 14$ UTC, $M_{\mathrm{w}} 8.4$ ), and the 15 August 2007 Pisco earthquake $\left(13.39^{\circ} \mathrm{S}, 76.60^{\circ} \mathrm{W}, 23: 40: 58 \mathrm{UTC}\right.$, $\left.M_{\mathrm{w}} 8.0\right)$. Seismic sequences and background seismicity from 2001 to 2007 are shown in Figure 1. The Centroid-Moment Tensor (CMT) point-source solutions for these events (Ekström, 2009) are consistent with shallow-dipping underthrusting ruptures separated by the Nazca ridge and the 12 November $1996 M_{\mathrm{w}} 7.7$ underthrusting event, with centroid time shifts relative to the U.S. Geological Survey origin times (previously given) of $69 \mathrm{sec}$ for the 2001 event and $60 \mathrm{sec}$ for the 2007 event, suggesting rupture durations on the order of two minutes for both events. The 2001 event aftershock sequence extends $\sim 270 \mathrm{~km}$ to the southeast from the hypocenter, and the CMT centroid is shifted $\sim 150 \mathrm{~km}$ in that direction. The 2007 event aftershock sequence is rather compact for a great earthquake, extending $\sim 150 \mathrm{~km}$ to the southeast from the hypocenter, while the CMT centroid is shifted $\sim 60 \mathrm{~km}$ seaward rather than along strike. The difference in aftershock zone lengths and the comparable centroid time shifts immediately suggest large differences in apparent rupture velocity for the two events.

The 2001 and 2007 great Peru earthquakes have been extensively studied using seismic, GPS, InSAR, and tsunami observations (Fig. 2). Our focus here is not on the tectonic 


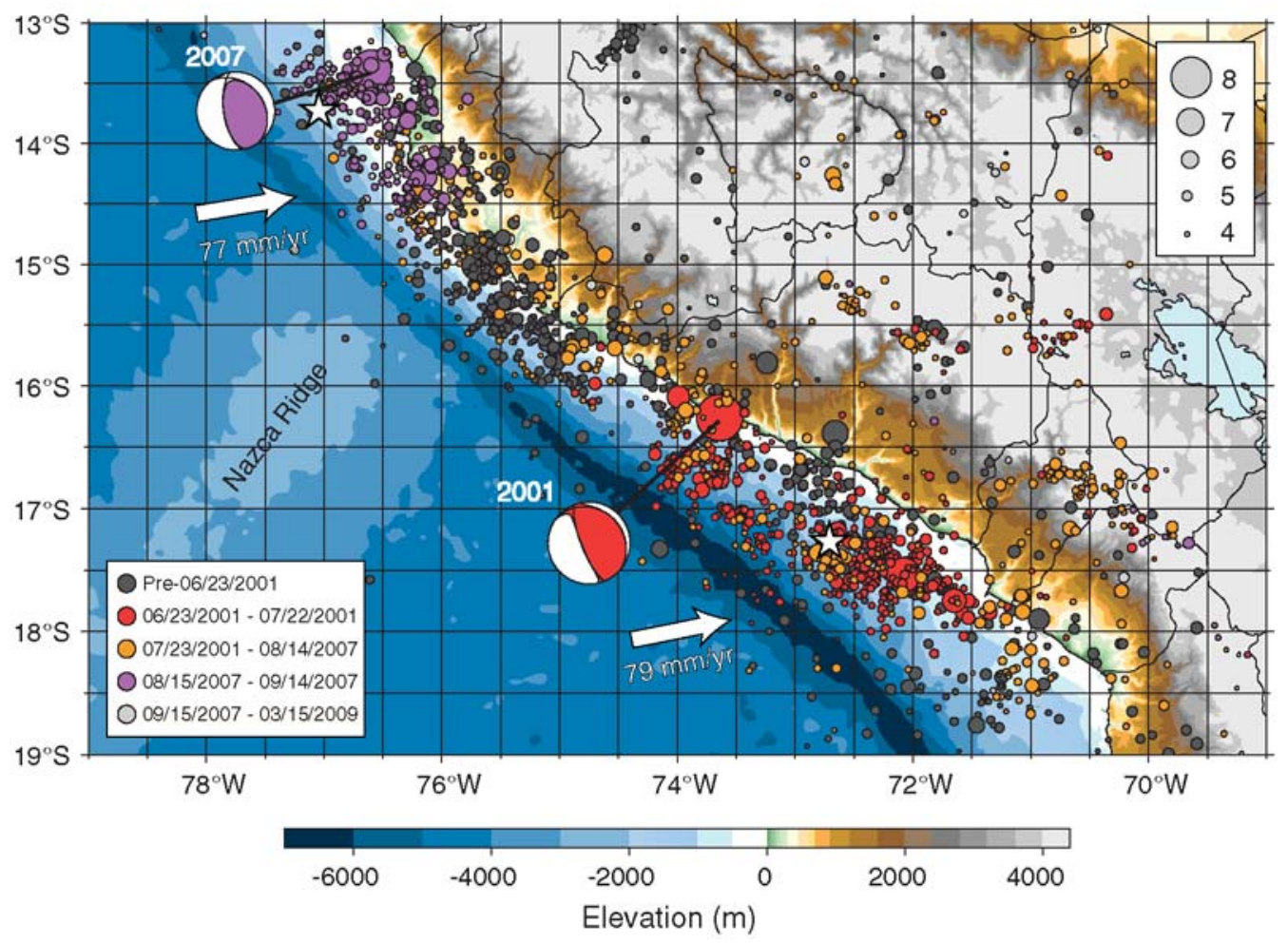

Figure 1. Seismicity along the Peru coastline prior to 16 March 2009 from the U.S. Geological Survey, along with CMT focal mechanisms for the 23 June 2001 (red) and 15 August 2007 (purple) great earthquakes, and their associated centroid-locations (white stars). The USGS hypocentral locations of the mainshocks are the two largest colored circles. Seismicity within one month after the 23 June 2001 event is indicated with red dots, while seismicity within one month after the 15 August 2007 event is indicated with purple dots. Black dots indicate seismicity before the two mainshock sequences, orange dots indicate seismicity in the time between the sequences, and gray dots are after the end of the 2007 sequence. Circles are scaled proportional to the seismic magnitude (the larger of $m_{b}$ or $M_{s}$ ).

implications or hazards of these large damaging earthquakes, as those have been extensively discussed. Rather, we focus on the space-time slip distribution estimated using teleseismic observations and their sensitivities, motivated by the differences in apparent rupture velocity, discrepancies noted in the following paragraphs in slip-models inferred from different data sets, and our own large aperture network back projections of teleseismic broadband signals. We begin with an overview of prior estimates of the slip-distributions for the two earthquakes from various procedures, demonstrating the existing discrepancies.

\section{Peru Earthquake}

Several finite-source rupture models for the 2001 Peru earthquake have been determined from seismic and/or geodetic and tsunami data (Fig. 2a,b provides reference solutions). Using a rapid finite-source linearized least-squares inversion (after Hartzell and Heaton, 1983) of $24 P$-wave signals, Kikuchi and Yamanaka (2001) obtained a 107-sec duration source process, with relatively weak radiation in the first $30 \mathrm{sec}$ followed by a large slip patch centered about $150 \mathrm{~km}$ to the southeast along the fault strike. The seismic moment estimate for $M_{0}$ was $2.2 \times 10^{21} \mathrm{Nm}$. A rupture velocity, $V_{r} \sim$ $2.5 \mathrm{~km} / \mathrm{sec}$ was assumed; thus, the slip model was effec- tively parameterized to have a primarily slip-pulse rupture expansion from the hypocenter at the northwestern edge of the fault model. Iterative pulse-stripping deconvolution inversions were applied to 14 and $18 P$ waves by Giovanni et al. (2002) and Bilek and Ruff (2002), respectively. This inversion imposes almost no kinematic constraints other than a (causality) maximum rupture velocity and the fault orientation. Giovanni et al. (2002) found an initial subevent located within $50 \mathrm{~km}$ of the hypocenter near the northwestern end of their model and a larger secondary subevent $130 \mathrm{~km}$ from the hypocenter, with an overall southeastward rupture expansion having $V_{r} \sim 1.6 \mathrm{~km} / \mathrm{sec}$. Their estimate of the seismic moment was $2.4 \times 10^{21} \mathrm{Nm}$. Bilek and Ruff (2002) computed a similar solution, but with the first subevent located at the hypocenter in the center of their fault model, and a large secondary rupture located $120-160 \mathrm{~km}$ to the southeast, with a total moment of $6.3 \times 10^{21} \mathrm{Nm}$ and $V_{r} \sim 1.6 \mathrm{~km} / \mathrm{sec}$. They also performed empirical Green's function deconvolution of Love and Rayleigh waves using signals from a large aftershock, estimating a rupture duration of $78 \mathrm{sec}$ and a unilateral rupture length of $138 \mathrm{~km}$ (giving $V_{r} \sim 1.8 \mathrm{~km} / \mathrm{sec}$ ). The latter estimates of the total duration and rupture length values are quite low; we show in the following paragraphs that these values are probably biased by inadequate recovery 
(a)

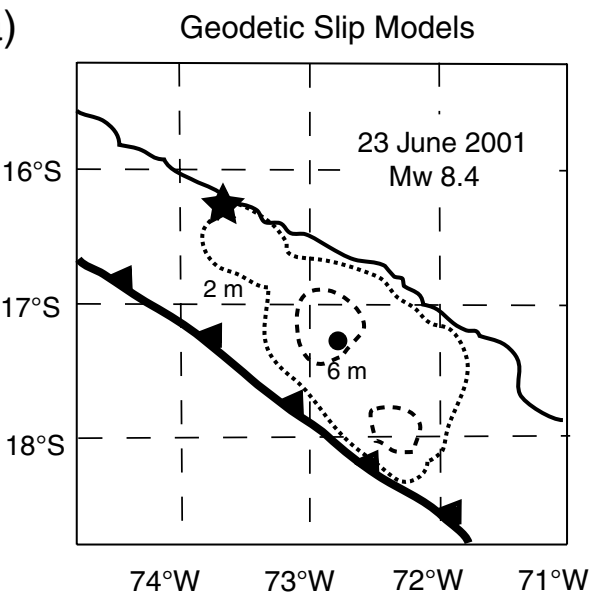

(c)

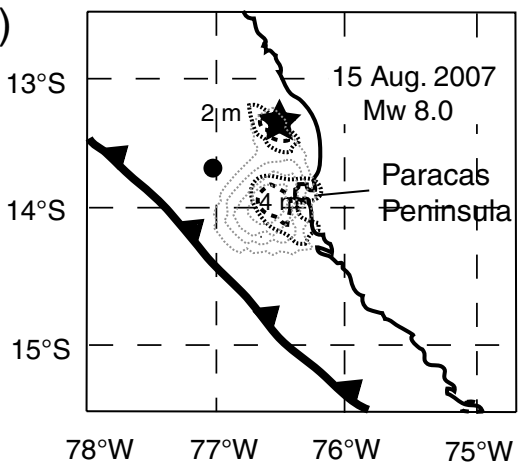

(b)

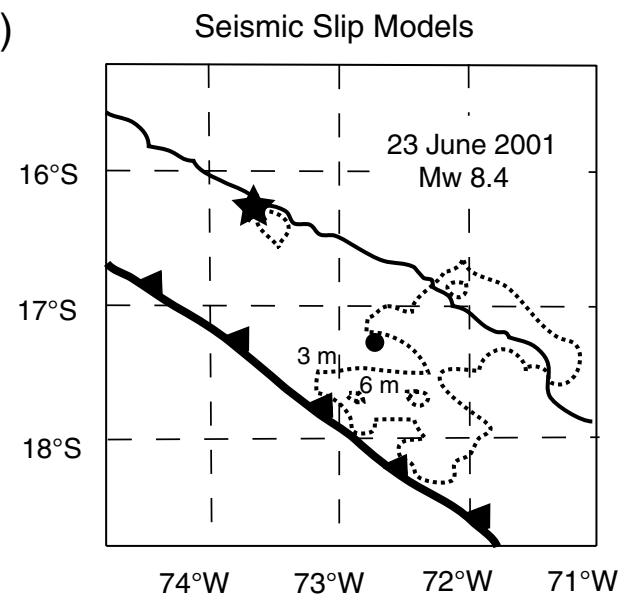

(d)

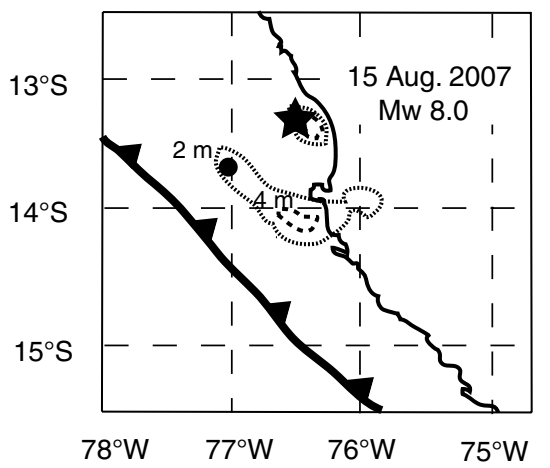

Figure 2. Summary of slip distribution characteristics for the 2001 (top row) and 2007 (bottom row) Peru earthquakes from prior work. Slip models from geodetic inversions are shown on the left and slip models from seismic wave inversions are shown on the right. In each panel the star indicates the USGS epicenter and the solid circle indicates the centroid location from the CMT solution. The approximate trench location is indicated by the toothed curve and the coastline by the lighter curve. (a) Coseismic displacement contours from joint inversion of GPS and InSAR data for the 2001 event from Pritchard et al. (2007). (b) Coseismic displacement contours from seismic wave inversions for the 2001 event from Pritchard et al. (2007). (c) Coseismic displacement contours from inversions of InSAR data for the 2007 event from Sladen et al. (2010) (contours labeled $2 \mathrm{~m}$ and $4 \mathrm{~m}$ ) and from Pritchard and Fielding (2008) (light contours). The latter solution is very similar to that from Biggs et al. (2009). (d) Coseismic displacement contours from seismic wave inversions for the 2007 event from Sladen et al. (2010).

of the low-frequency spectra of the mainshock surface wave source functions, most likely a result of limited lowfrequency signal in the empirical Green's function.

Robinson et al. (2006) performed a finite fault inversion of segments of $19 \mathrm{SH}$ waves, 7 of which extended for at least $120 \mathrm{sec}$, using an algorithm (Das and Kostrov, 1990) that allows subfaults to repeatedly rupture throughout the overall duration. They find a spatially complex slip distribution, which begins with a unilateral rupture propagating with a rupture velocity of $\sim 3.5 \mathrm{~km} / \mathrm{sec}$ to $\sim 70 \mathrm{~km}$ to the southeast, which circumvents a $\sim 6000-\mathrm{km}^{2}$ barrier, and propagates further to the southeast. After $54 \mathrm{sec}$ the initially unbroken barrier begins to fail, with large slip in the up-dip region and an average rupture velocity of $\sim 2.8 \mathrm{~km} / \mathrm{sec}$. About $200 \mathrm{~km}$ to the southeast of the hypocenter, a second barrier is encircled by the initial rupture between $\sim 36$ and $60 \mathrm{sec}$ and then breaks about $66 \mathrm{sec}$ after rupture initiation. Slip continues near the hypocenter for the entire rupture duration.
Pritchard et al. (2007) inverted 80-sec long windows of $18 P$ and $13 \mathrm{SH}$ waveforms (weighted twice as much as the $P$ waves) using the method of Ji et al. (2002), which prescribes a rupture velocity range and subfault source-time functions. They allowed a range of rupture velocities from 2.2 to $3.8 \mathrm{~km} / \mathrm{sec}$, defining the interval during which subfaults could slip. They obtain a slip model (Fig. 2b) with a patch of slip near the hypocenter, and slip patches both up-dip and down-dip about $150 \mathrm{~km}$ to the southeast, with a total seismic moment of $6.2 \times 10^{21} \mathrm{Nm}$ and an average rupture velocity of $2.7 \mathrm{~km} / \mathrm{sec}$. There is virtually no slip in the model between the hypocenter and the region of large slip to the southeast. Inclusion of records from two strong motion records at some distance from the rupture zone did not change the solution appreciably. However, inversion of two continuous and 12 campaign GPS stations and/or inversion of InSAR data indicated significantly more slip between the hypocenter and $150 \mathrm{~km}$ along the trench (near the CMT centroid location) 
than the seismic models (Fig. 2a). The geodetic seismic moment estimates range from 4.0 to $8.3 \times 10^{21} \mathrm{Nm}$, but could equal the seismic estimate. Joint inversion of the seismic and geodetic data essentially averaged the slip patterns of the two solutions. Pritchard et al. (2007) argue that the differences in the geodetic and seismic inversions are due to different inherent abilities to resolve slip, possibly due to slow slip in the region between the hypocenter and the CMT centroid location being missed by the seismic data and due to shallow, far offshore slip being undetectable by the geodetic data.

Overall, the previously published models for the 2001 Peru event all support southeastward expansion of the rupture, but there are significant discrepancies. Some models have very little slip within $\sim 150 \mathrm{~km}$ of the hypocenter, some with unusually low rupture velocities of $1.5-1.8 \mathrm{~km} / \mathrm{sec}$ have significant slip about $120-130 \mathrm{~km}$ from the hypocenter, and others have slip occurring late in the rupture process close to the hypocenter. There is clearly a large pulse of seismic radiation about $60 \mathrm{sec}$ into the rupture; it is worth noting that any imposed slip-pulse-type constraint forces associated model slip to be placed at significant distance from the source (e.g., for $V_{r}=2 \mathrm{~km} / \mathrm{sec}$, there can be no associated slip within $120 \mathrm{~km}$ of the source if the subfault rupture durations are specified to be short). There is concern raised by the discrepancies in seismic and geodetic models; if the seismic data are truly blind to substantial amounts of the slip, they may lead to underestimation of the tsunamigenesis.

\section{Peru Earthquake}

Finite-source models for the 2007 Peru event have also been produced by several groups using seismic and/or geodetic data (Fig. 2c,d provides reference solutions). Among the rapidly produced seismic inversions are models produced by Ji and Zeng (2007), Yagi (2007), Yamanaka (2007), and Vallée (2007). These models established the basic character of the slip distribution as having a patch of slip concentrated near the hypocenter at about $39 \mathrm{~km}$ depth, with a large secondary patch of slip centered up-dip and southwest from the hypocenter at a distance of about $60-100 \mathrm{~km}$ away. The solution from Ji and Zeng (2007) fit both body and surface waves and has an average $V_{r} \sim 1.5 \mathrm{~km} / \mathrm{sec}$ and $M_{0}=$ $1.8 \times 10^{21} \mathrm{Nm}$, Yagi (2007) inverted body waves only, finding an average $V_{r} \sim 1.3 \mathrm{~km} / \mathrm{sec}$ and $M_{0}=2.0 \times 10^{21} \mathrm{Nm}$, and Yamanaka (2007) inverted body waves to find an average $V_{r} \sim 1.0 \mathrm{~km} / \mathrm{sec}$ and $M_{0}=1.9 \times 10^{21} \mathrm{Nm}$. The higher the average rupture velocity, the further from the hypocenter the secondary slip is distributed in these models, directly affecting the location of large slip relative to the Paracas peninsula (Fig. 2c; Ji and Zeng's model places the main slip well south of the peninsula; Yagi's solution puts it just south, as does Vallée's; and Yamanaka's solution puts it right at the peninsula). The location of this slip is important for anticipation of where tsunami run-ups might be expected, with the observed run-ups being up to $10 \mathrm{~m}$ on the southern side of the Paracas peninsula near Rancherio (Fritz et al., 2008), most consistent with the slip model of Ji and Zeng (2007).

InSAR observations were inverted along with teleseismic $P$ and $S H$ observations by Pritchard and Fielding (2008), with the InSAR data indicating a main slip patch about $70 \mathrm{~km}$ from the hypocenter, southwest of the Paracas peninsula (Fig. 2c). The teleseismic data show a strong secondary energy release 60-90 sec after the rupture initiation, indicating a rupture velocity less than $1.5 \mathrm{~km} / \mathrm{sec}$. Inversion of just the teleseismic data using $V_{r}$ in the range $2-4 \mathrm{~km} / \mathrm{sec}$ gave a complex slip distribution with significant down-dip slip and slip far from the hypocenter, whereas the InSAR-only inversion gave a large slip patch just offshore, close to the hypocenter. Simultaneous inversion, in which $V_{r}$ was allowed to vary from 0.1 to $3.5 \mathrm{~km} / \mathrm{sec}$, concentrated the slip closer to the InSAR solution, but the fit is still degraded from the InSAR-only solution. Pritchard and Fielding (2008) prefer the interpretation that the event has a low rupture velocity of about $1.3 \mathrm{~km} / \mathrm{sec}$. Motagh et al. (2008) inverted the InSAR data and found slip from near the hypocenter to far offshore near the CMT centroid location, with no clear separation into two asperities.

Biggs et al. (2009) inverted 18 teleseismic $S H$ records using the method of Das and Kostrov (1990), as well as InSAR data, finding very different slip models. Their seismic model has large slip near the epicenter, up-dip, and well to the south, whereas their InSAR model has a single large patch of slip offshore of the Paracas peninsula similar to that found by Pritchard and Fielding (2008) and Motagh et al. (2008). They find slip occurring very late near the hypocenter, which is precluded from the expanding rupture annulus models used in the rapid inversions. The slip history is very erratic, without any clear sense of a rupture velocity (other than causality) governing slip history over the fault. No clear explanation for discrepancies between the seismic and geodetic models was provided.

Sladen et al. (2010) drew upon InSAR, teleseismic body waves, tsunami waveforms, coastal deformation, and run-up observations to find a suite of slip models for the event. They prefer a solution with two slip patches, a small one near the hypocenter and a larger one about $60 \mathrm{~km}$ south near the Paracas peninsula. The seismic waves were modeled using the method of Ji et al. (2002) using either a range of low rupture velocities $(0.8-1.2 \mathrm{~km} / \mathrm{sec})$ or a delay of $38 \mathrm{sec}$ between two separate ruptures. The secondary slip patch is smeared along the 60 -sec rupture isochron (average position of the rupture front), similar to the rapid solutions (Fig. 2d), so it is not as concentrated as in the InSAR solutions (Fig. 2c). Simultaneous inversion of InSAR and seismic data yield two slip-patch models for both the low rupture velocity and earthquake doublet approaches; these successfully match the tsunami records. Sladen et al. (2010) note that there is no clear indication of low rupture velocity or tsunamiearthquake character for the Pisco event, so they consider the triggering processes that might account for the delay in a doublet rupture. 
Again, at face value, the solutions for the 2007 Peru event are contradictory and suggest limited agreement between geodetic and seismic models. While all of the studies involve differences in seismic velocity structures, seismic data sets, model smoothing, and precise fault orientations, we expect such effects are secondary relative to basic inversion formulation and imposed kinematic constraints. While some models appear to reconcile geodetic and seismic observations to a certain extent, it is important to understand the intrinsic limitations of the teleseismic data and any inability to resolve the coseismic slip.

\section{Back-Projection Images of the Source Rupture History}

Many seismic studies have demonstrated that earthquake ruptures are complex frictional instabilities, with a wide range of slip behavior. While there is much support for propagating dislocation representations of failure, processes such as dynamic triggering, afterslip, slow slip, segment jumping, and other complex phenomena are also well documented. Thus, it is appealing to seek constraints on large earthquake rupture histories with minimal a priori assumptions about the space-time history of failure, if it is possible to avoid unstable solutions. This is not trivial. Back-projection and reverse-time methods allow data differential timing to image loci of coherent radiation from a source region that may reveal overall rupture processes. The value of this was dramatically demonstrated for the great 2004 Sumatra earthquake by Ishii et al. (2005), who back projected short-period $P$-wave radiation recorded across the large aperture Hi-net stations in Japan to track the predominantly unilateral rupture expansion from Sumatra to the Andaman Islands. Further development of such approaches (e.g., Krüger and Ohrnberger, 2005; Walker and Shearer, 2009; Xu et al., 2009) using both regional and global networks provide space-time models of rupture evolution that exploit the same small changes in timing of seismic arrivals that provide the resolution of finite-source models. Backprojection images do not yield actual slip distributions or moment estimates because they do not quantitatively account for the Green's function influences on seismic wave energy partitioning, but they can provide overall characterization of source finiteness that may influence parameterization of finite-source modeling. There are some similarities with time-reversal imaging approaches (e.g., Larmat et al., 2006; Kawakatsu and Montagner, 2008; Anderson et al., 2009), but $P$ wave back projections assume simple optical travel time effects and do not account for propagation losses. $S$ wave back projections are not attempted due to the large path travel time anomalies that create difficulty in phase alignment. We consider the implications of teleseismic back projections for the two great Peru earthquakes, using global network $P$-wave recordings, because the events are not favorably oriented relative to any one large regional array.

\section{Peru Earthquake}

We back projected 168 teleseismic (epicentral distances $\left.30^{\circ}-95^{\circ}\right) P$ waves from broadband stations in North America (133), Antarctica (6), Atlantic islands (10), Europe (13), and Africa (6) to the source region for the 2001 event following procedures similar to those in $\mathrm{Xu}$ et al. (2009). A uniform depth grid of back-projection points is defined spanning the source region; the initially aligned teleseismic signals are shifted and summed at each grid point based on differential travel times computed for a standard Earth model. Pacific island observations were excluded because of nodal $P$-wave radiation and rapid changes in the waveform coherence. The retained data sample a stable portion of the $P$-wave compressional radiation quadrant with relatively similar Green's functions. The data were weighted inversely proportional to the number of stations within $1000 \mathrm{~km}$ distance from each observation to balance the data importance (Walker and Shearer, 2009). This suppresses back-projection artifacts caused by the nonuniform distribution of the stations. Additional weighting of the data by their azimuthal distribution did not significantly affect the results for this event. The data were band-pass-filtered between 0.05 and $0.4 \mathrm{~Hz}$, and cross-correlated with each other to ensure stability of polarity, coherence, and initial time alignment. In order to increase image coherence, results were calculated in time steps of $0.25 \mathrm{sec}$ and then averaged over $6 \mathrm{sec}$. The values chosen provide stable images with minimal smearing and artifacts due to the favorable radiation pattern, which produced coherent arrivals across four continents. Other choices of spatial and temporal averaging, weighting, filtering, and stacking (nth-root) were tested and produced similar results. The time-varying linear stack back projections are included; key frames from the animation are shown in Figure 3. The station distribution and full animation are shown (E) in movies 1 and 2 in the electronic edition of BSSA. The effects of the station weighting are shown in (E) movie 5 in the electronic edition of BSSA.

The rupture images indicate weak initial radiation near the hypocenter, a coherent burst $50 \mathrm{sec}$ later $\sim 150 \mathrm{~km}$ to the southeast, a large burst at $76 \mathrm{sec}$ centered about $110 \mathrm{~km}$ from the hypocenter, continuing radiation from the fault region migrating slowly toward the hypocenter for the next $30 \mathrm{sec}$, and then isolated late up-dip/trenchward radiation $\sim 30 \mathrm{sec}$ later. The unaccounted for Green's function effects of variable depth and wedge structure on the signals and expected degradation of signal coherence with lapse time into the rupture undoubtedly contaminate the image of the rupture process; however, some general attributes are suggested. The event can be interpreted as an initial small event that triggered a larger secondary event located southeastward on the megathrust upon arrival of the $S$ wave or the Rayleigh wave. The rupture then expanded back toward the initial hypocenter at depth, and then up-dip toward the trench. There is a hint of smooth rupture expansion southeastward from the hypocenter in the first $40 \mathrm{sec}$, but the back-projection stack 


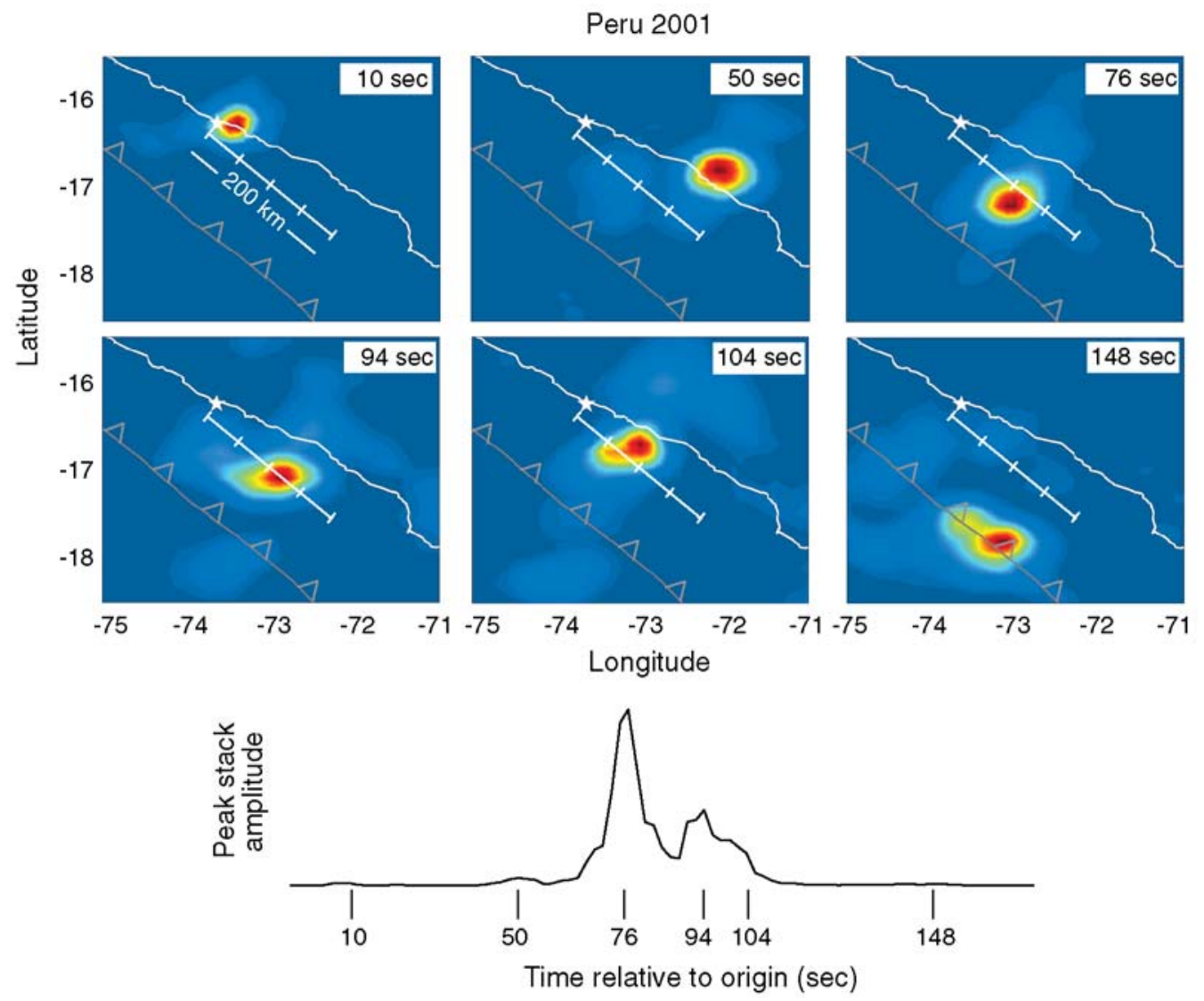

Figure 3. Six images from the rupture sequence for the 2001 event formed by back projecting and linearly stacking $168 P$-wave recordings from a global array of broadband stations $30^{\circ}-95^{\circ}$ away covering $\sim 180^{\circ}$ in azimuth. Warm colors identify regions of coherent $P$-wave radiation across the receiving array, with the peak amplitudes being normalized in each panel (relative amplitudes between panels are indicated by the peak amplitude trace shown at the bottom). Each panel is a snapshot integrated over a 6-sec time window at times of local radiation maximum in the time history of peak stack amplitudes shown in the peak amplitude trace. The time-varying peak stack amplitude over all grid points is a crude approximation of the source-time function and is influenced by both phase amplitude (i.e., moment release) and signal coherence. The star in each image is the NEIC epicenter. The coast is identified by a thick white line, the megathrust plate boundary by a toothed gray line, and the time relative to the hypocentral time is given in the upper right corner of each panel. (E) Animations of the back projection are in movie 1 (uniform amplitude scale) and movie 2 (each frame peak amplitude scale renormalized), and the effects of station weighting are shown in movie 5 in the electronic edition of BSSA.

amplitudes are low and even fall below the background level at some time steps, so continuity of radiation is unclear. Overall, this is clearly a different time sequence than accompanies the finite-source models with kinematically constrained slip-pulse-type attributes.

\section{Peru Earthquake}

A similar distribution of 92 filtered $P$-wave signals from teleseismic distances $\left(30^{\circ}-95^{\circ}\right)$ was back projected for the 2007 event. Again, the station distribution and movie of time-varying images are provided in (E) movies 3 and 4 in the electronic edition of $B S S A$; the key frames are shown in Figure 4 . The event initiated with rupture beneath the coastline north of the Paracas peninsula. About $52 \mathrm{sec}$ later, a second, larger release of energy occurred near the peninsula. High-frequency radiation slowly migrated back toward the northwest for the next $40 \mathrm{sec}$, suggesting low rupture velocity and a change of rupture front direction. The compact nature of the energy release is readily apparent in these backprojection images; this could have guided specification of the faulting area for finite-source models even before aftershocks suggested the surprisingly small source area for a magnitude 8.0 event. Data weighting effects are shown in (E) movie 5 in the electronic edition of BSSA.

\section{Body-Wave and Surface-Wave Rupture Models with Varying Kinematic Constraints}

Our back-projection results, while not fully quantifying true slip distributions, suggest that some of the discrepancies between different finite-source models may result from assumptions imposed on the kinematics of the rupture models for the 2001 and 2007 Peru events. We focus on just the seismic inversions here, noting that there is better agreement among the geodetic inversions, or at least reasonable explanations for the discrepancies that exist between InSAR and GPS solutions for both events. We collected large, high-quality 


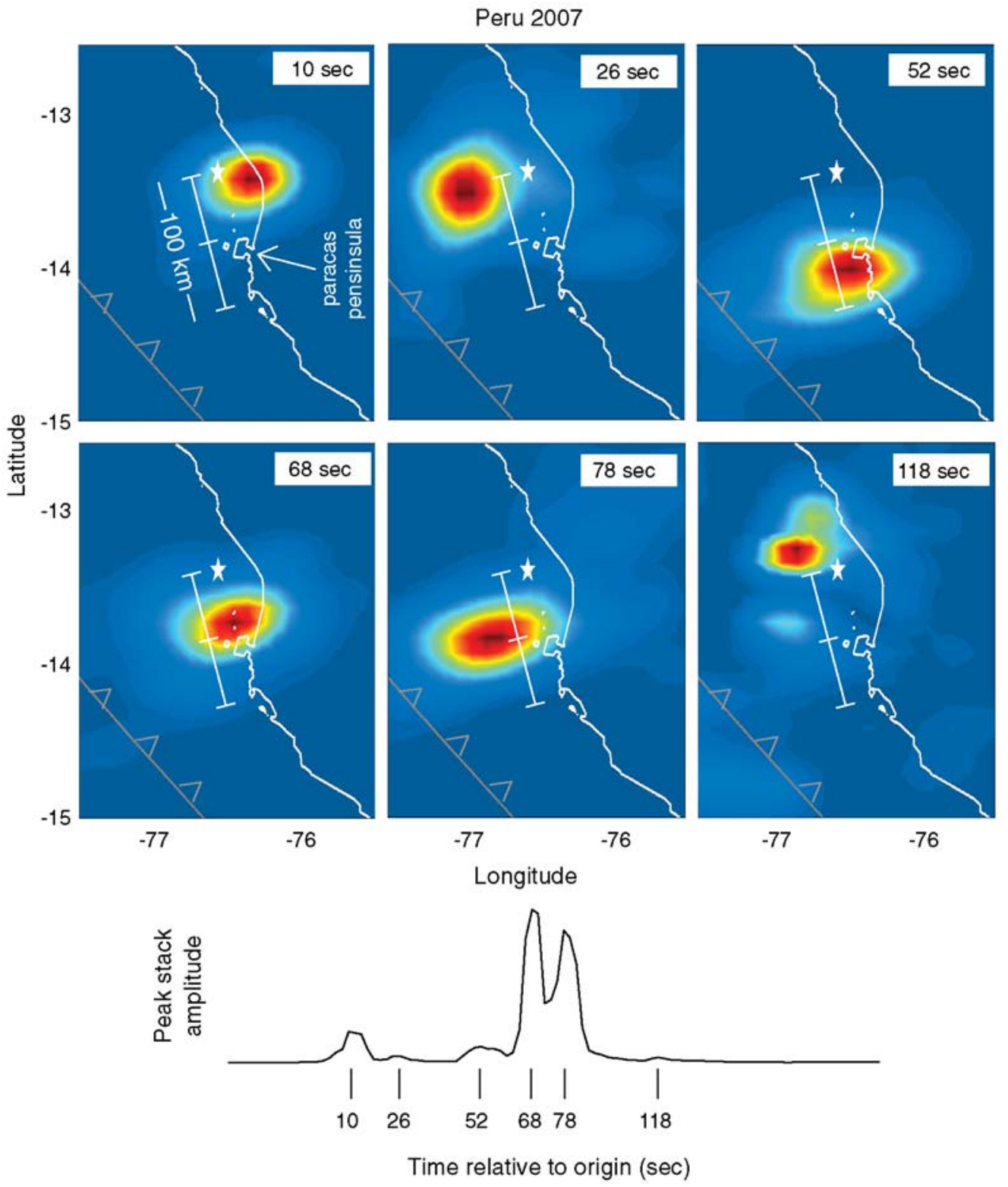

Figure 4. Six images from the rupture sequence for the 2007 event formed by back projecting and linearly stacking $92 P$-wave recordings from a global array of broadband stations $30^{\circ}-95^{\circ}$ away covering $\sim 180^{\circ}$ in azimuth. Warm colors identify regions of coherent $P$-wave radiation across the receiving array, with the peak amplitudes being normalized in each panel (relative amplitudes between panels are indicated by the peak amplitude trace shown at the bottom). The images have the same format as in Figure 3. (E) Animations of the back projection can be viewed in movie 3 (uniform amplitude scale) and movie 4 (each frame peak amplitude scale renormalized), and the effects of station weighting are shown in movie 5 in the electronic edition of BSSA.

data sets of broadband $P$ and $S H$ waves along with short-arc Rayleigh waves (R1) to construct new seismic models guided by the apparent need for greater kinematic flexibility in the finite-source inversion regularization suggested by the backprojection results.

\section{Peru Earthquake}

The 2001 earthquake is large enough that even the longperiod surface waves may be affected by source finiteness, so we confirmed the overall source geometry and seismic moment by inverting 44 recordings of teleseismic $W$-phase ground displacements (Kanamori and Rivera, 2008) for the passband $0.001-0.005 \mathrm{~Hz}$. This gave a solution with $M_{0} 5.5 \times$ $10^{21} \mathrm{Nm}\left(M_{\mathrm{w}} 8.4\right)$ and a best double-couple geometry with strike, $\phi=306^{\circ}$, dip, $\delta=14^{\circ}$, and rake, $\lambda=54^{\circ}$, generally compatible with the CMT inversion $\left(M_{0} 4.7 \times 10^{21} \mathrm{Nm}\right.$, $\left.\phi=310^{\circ}, \delta=18^{\circ}, \lambda=63^{\circ}\right)$. The $W$-phase solution has an optimal centroid location southeast of the hypocenter near the CMT centroid. Extending the passband to $0.001-0.05 \mathrm{~Hz}$ had only minor effects, and yielded $M_{0} 5.4 \times 10^{21} \mathrm{Nm}, \phi=$ $313^{\circ}, \delta=13^{\circ}$, and $\lambda=65^{\circ}$. We adopt the geometry of the 
CMT solution (or just the corresponding strike and dip, while allowing rake to vary) in all of our finite-source modeling for the 2001 event, noting that there is an expected trade-off between fault dip and seismic moment and a possibility of increasing dip with depth (e.g., Pritchard et al., 2007). In general, small changes in fault geometry on the order of $10^{\circ}$ for $\phi$, $\delta$, or $\lambda$ are not resolvable in teleseismic finite-source inversions as the many parameters in the models can trade-off.

Intermediate period $(30-300 \mathrm{sec})$ surface waves are relatively sensitive to gross finite-source properties and directivity (e.g., Ammon et al., 2006), so we analyze shortarc (R1) Rayleigh waves from Global Seismic Network stations to evaluate first-order rupture finiteness effects. We use the same procedures as described in Lay et al. (2009) to extract effective source-time functions for each R1 signal by deconvolving a point-source synthetic computed for the PREM (Dziewonski and Anderson, 1981) structure, corrected for aspherical phase velocity heterogeneity (Boschi and Ekström, 2002), and filtered with a Gaussian filter [exp $\left.\left(-\omega^{2} / 4 a^{2}\right)\right)$, where $\omega$ is frequency and $a=0.05$ ] to emphasize periods longer than $\sim 40 \mathrm{sec}$. The resulting R1 effective source-time functions are shown in Figure 5, plotted as a function of the directivity parameter, $\Gamma=\cos \left(\phi_{\mathrm{sta}}-\phi_{r}\right) / c$, where $\phi_{\text {sta }}$ is the station azimuth, $\phi_{r}$ is a unilateral rupture azimuth taken to be along the negative fault strike of $130^{\circ}$, and $c$ is a reference phase velocity ( $c$ is chosen as $4.0 \mathrm{~km} / \mathrm{sec}$, the phase velocity for 80 -sec period Rayleigh waves for model PREM).

Observations near the $\Gamma$ extremes of $\pm 0.25 \mathrm{sec} / \mathrm{km}$ (the positive value is for station azimuth along the rupture direction, while the negative value is directly opposite to it) are less reliable because these data leave the source near $\mathrm{R} 1$ radiation nodes; noise levels in the deconvolutions are higher and the convolutional model fits to the observations are lower than for data recorded at azimuths away from radiation nodes. Extrapolating trends across all the data gives estimates of maximum duration, $T_{\max } \sim 210 \mathrm{sec}$, minimum duration, $T_{\min } \sim 150 \mathrm{sec}$, and average duration, $T_{\mathrm{avg}} \sim$ $180 \mathrm{sec}$. The Gaussian filter broadens impulsive signals by $50-60 \mathrm{sec}$, so the durations are correspondingly increased. These values have substantial uncertainty, in part due to residual misalignments in the data that are difficult to objectively suppress due to the emergent onset of many of the source functions. A reasonable estimate of uncertainty on the differential duration measures is $\pm 15 \mathrm{sec}$. The deconvolved R1 source-time functions are much smoother and of longer duration than those obtained by Bilek and Ruff (2002), which we attribute to better recovery of the very long-period components enabled by use of low-noise theoretical Green's functions rather than empirical Green's functions (for which the intrinsic excitation of long-periods for the small event is too weak to provide a good signalto-noise ratio in the ratio of mainshock to small event spectra). For a simple unilateral rupture model, the fault length, $L$, can be estimated from $L=c\left(T_{\max }-T_{\min }\right) / 2$, for which we obtain $L \sim 120 \mathrm{~km}$, which is only about $1 / 2$ the length of the aftershock zone. If we assume a source function rise time, $\tau$, we can estimate the rupture velocity $V_{r}=L /\left(T_{\text {avg }}-\tau\right)$. For zero rise time, and even allowing for a 50 -sec broadening due to filtering, we get $V_{r} \sim 0.9 \mathrm{~km} / \mathrm{sec}$, as a lower bound.

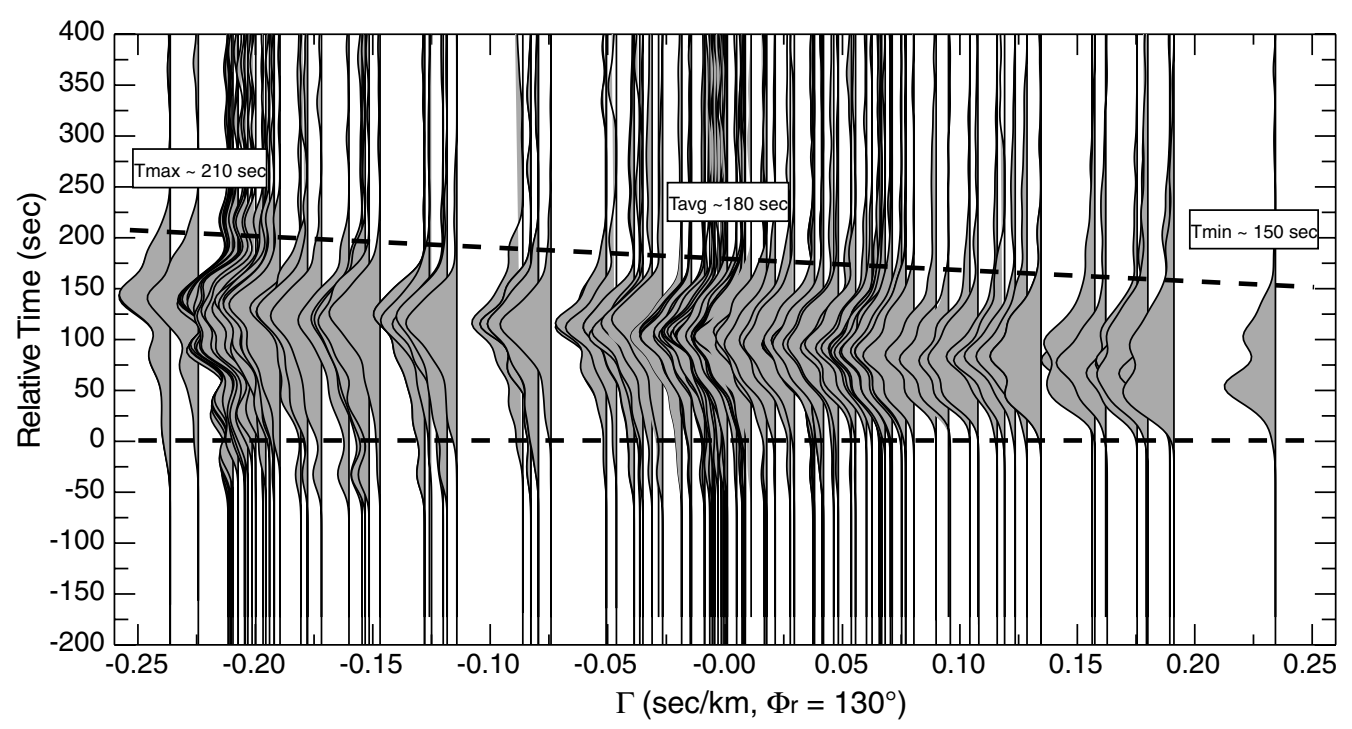

Figure 5. Effective Rayleigh wave (R1) source-time functions for the 2001 Peru event obtained by iteratively deconvolving point-source synthetics computed for the CMT best double couple with strike $310^{\circ}$, dip $18^{\circ}$, and rake $63^{\circ}$, and a source depth of $15 \mathrm{~km}$ from the data using a positivity constraint. The synthetics for the PREM structure were corrected for aspherical phase velocity heterogeneity. The deconvolutions have been convolved with a Gaussian filter with averaging width 0.05 which broadens the source functions by 50-60 sec. The onset times have been adjusted by a 25 -sec shift but small misalignments from inaccuracy of the propagation corrections affect the relative times. The source functions are plotted as a function of the directivity parameter, assuming a rupture azimuth along the trench at $130^{\circ}$. For a reference phase velocity of $4.0 \mathrm{~km} / \mathrm{sec}$, the estimated $T_{\max } \sim 210 \mathrm{sec}, T_{\min } \sim 150 \mathrm{sec}$. The estimated $T_{\mathrm{avg}} \sim 180 \mathrm{sec}$. The duration measures are all increased by $50-60 \mathrm{sec}$ by the Gaussian filter. 
For $\tau=0.10 T_{\text {avg }}$, we get $V_{r} \sim 1.0 \mathrm{~km} / \mathrm{sec}$. These rupture velocity estimates are quite low, indicating that either the event was a slow rupture or that the assumption of unilateral rupture is incorrect. We believe the latter is the actual explanation, and basically infer from the R1 signals that this event did not have significant slip over the full length of the aftershock zone and is not consistent with a simple unilateral rupture behavior. This inference is supported by consideration of the shapes of the source functions at different azimuths; the source functions are not simply time-stretched versions at different azimuths as expected for a unilateral rupture; there must be some component of bilateral radiation within the later portions of the rupture to match the signals. Although the simple 1D rupture based directivity analysis is of limited use on this earthquake, R1 source functions can be computed for any finite-source solution and compared with the observations, as shown in the text that follows, to ensure consistency with the long-period radiation from the source.

Our large teleseismic broadband body-wave data set was ultimately pared down to $26 P$ waves and $20 \mathrm{SH}$ waves with good azimuthal distribution. In all of our inversions, the $S H$ waves are down-weighted by a factor of 5 , to approximately equalize the amplitudes relative to the $P$ waves. The $P$ wave onsets for this event are more impulsive than the $S H$ waves, and relative alignments are more reliable (this is important; only a few seconds of directivity controls the finite-source solutions and $S H$ onsets often have large uncertainty). We performed inversions of just $P$ waves and of joint $P$ - and $S H$-wave data sets, with the $S H$ alignments being slightly adjusted to match predictions from initial $P$ wave only models. The signal windows were 127 -sec long from the origin time, bounded mainly by avoiding large $S c S$ arrivals from strong secondary pulses in the source functions. Longer inversions of up to $170 \mathrm{sec}$ of signals were performed with just the $P$ waves. We apply four different styles of finite-source inversions to each data set: iterative wavelet-stripping deconvolution, linear inversion with slip-pulse-type models, linear inversion with crack-type (long subfault duration) models, and a linear inversion assuming an earthquake doublet (twosource) with separate slip-pulse-type model. Each approach imposes different kinematic constraints on the rupture; we evaluate which attributes of the finite-source models appear to be robust.

Iterative deconvolution for the 2001 Peru event returns solutions similar to that in Figure 6, where 40 subevents having symmetric triangular source functions (5-sec rise, 5 -sec fall) on a grid of point-sources with the CMT fault orientation were obtained from the 46 teleseismic body waves. A causality rupture velocity upper bound of $3.46 \mathrm{~km} / \mathrm{sec}$ was assumed, as this is the shear velocity at the hypocenter in our layered source crustal model. The fault-normal sourcetime function shown in the figure has low moment rate during the first $40 \mathrm{sec}$ of the event, a large pulse from 40 to $80 \mathrm{sec}$, and minor radiation extending as late as $120 \mathrm{sec}$. The $M_{0} 1.8 \times 10^{21} \mathrm{Nm}$ is lower than most estimates for this event. The primary pulse is associated with a patch of sub-

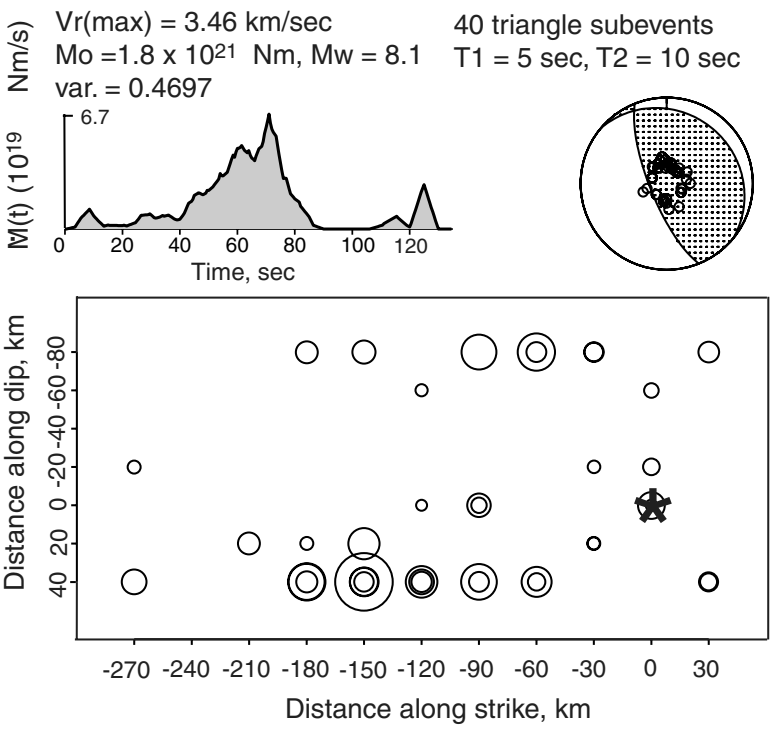

Figure 6. Spatial distribution of subevents for the 2001 Peru earthquake rupture obtained by iterative deconvolution of 46 teleseismic $P$ and $S H$ waves. Forty subevents with triangle source-time functions with 5-sec rise time (T1) and 10-sec durations (T2) were solved for. The focal mechanism shown was fixed for all subevents and is the best double couple from the CMT solution, with strike $310^{\circ}$, dip $18^{\circ}$ and rake $63^{\circ}$. The lower hemisphere projection of the station distribution is shown in the focal mechanism. The hypocentral depth was $29.6 \mathrm{~km}$. The residual variance in the waveform misfit (var.) was 0.4697 after 40 iterations. The asterisk indicates the hypocenter and circles are scaled proportional to the subevent seismic moments. The fault-normal far-field moment rate function for the composite sequence is indicated at the top left, and was constrained to have a maximum duration of $130 \mathrm{sec}$. (E) Waveform fits for this model are shown in Figure $\mathrm{S} 1$ in the electronic edition of BSSA.

events from 90 to $180 \mathrm{~km}$ to the southeast from the $29.6 \mathrm{~km}$ deep hypocenter, at slightly greater depth, and the overall rupture velocity is about $2.0-2.5 \mathrm{~km} / \mathrm{sec}$. The waveform mismatch (the ratio of misfit power to signal power) residual variance for this model is 0.47 , a relatively high value; this decreases very slowly with further iterations with the seismic moment estimate slowly growing. Waveform fits for the model in Figure 6 are shown in (E) Figure S1 in the electronic edition of $B S S A$. Very similar inversion results were obtained for different subevent source functions using triangular and trapezoidal shapes. The basic features are compatible with the earlier iterative inversions by Giovanni et al. (2002) and Bilek and Ruff (2002), but the specific location of subevents is not very stable; we can infer only that there was a large slip patch at a distance of $\sim 90-180 \mathrm{~km}$ from the hypocenter from 40 to $80 \mathrm{sec}$ into the rupture. The back-projection result suggests that high-frequency energy radiated from about $150 \mathrm{~km}$ southeast of the initial radiation about $50 \mathrm{sec}$ after rupture onset, so this attribute is supported, but the time sequence of later subevents in the iterative deconvolution is not considered sufficiently stable to relate further to the back-projection images.

At the opposite end of the spectrum of kinematic constraints are the slip-pulse or narrow-slip annulus rupture 
models, defined by a constant rupture velocity and relatively short duration subfault source-time functions. For teleseismic body-wave observations alone, this parameterization produces finite-source models with slip distributed over the portions of the rupture isochron favored by directivity in the observations. Thus, they intrinsically have strong trade-offs between prescribed rupture velocity and spatial location of the slip. A linearized inversion for the activated subfault slip parameters for each time step in the data is performed, with minor smoothness constraints on the slip distribution being imposed. The strike and dip are fixed to the CMT values, but the rake is allowed to vary within $\pm 45^{\circ}$ of the CMT rake for each subfault. Results for the 2001 Peru event assuming rupture velocities of $1.5,2.0,2.5$, and $3.11 \mathrm{~km} / \mathrm{sec}$ are shown in Figure 7. The highest rupture velocity considered is 0.9 times the shear velocity at the hypocenter, or approximately the Rayleigh wave velocity. The subfault source-time functions were parameterized with nine 4-sec duration triangles with variable moment lagged by 2 sec each, for maximum subfault durations of $20 \mathrm{sec}$. These models all produce almost identical overall source-time functions (the one shown in Fig. 7 is for the case with $V_{r}=2.5 \mathrm{~km} / \mathrm{sec}$ ), and very similar average rake values. The data fit from each solution are acceptable given the relatively simple assumptions regarding

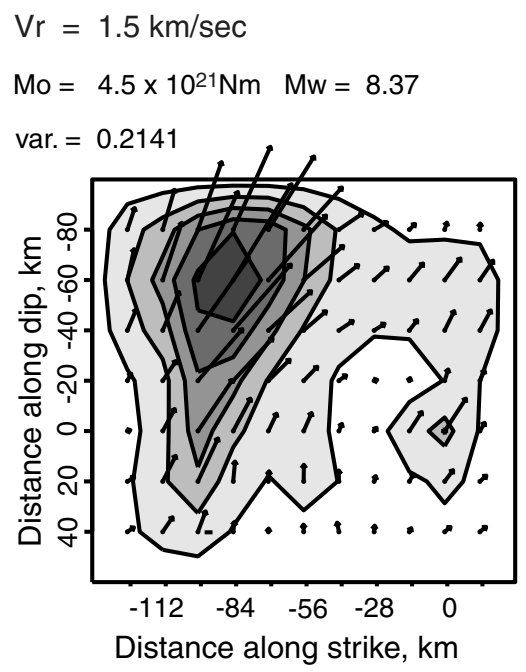

$\mathrm{Vr}=2.0 \mathrm{~km} / \mathrm{sec}$

$\mathrm{Mo}=4.2 \times 10^{21} \mathrm{Nm} \mathrm{Mw}=8.35$

var. $=0.1886$

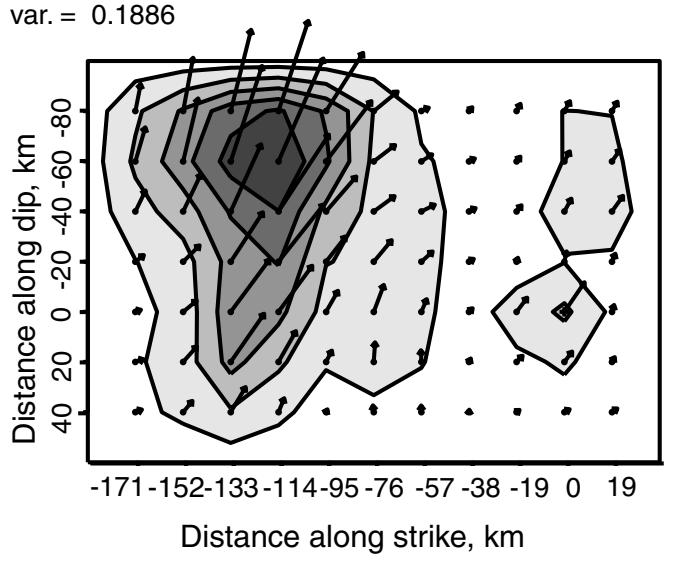

$\mathrm{Vr}=2.5 \mathrm{~km} / \mathrm{sec}$

$\mathrm{Mo}=4.0 \times 10^{21} \mathrm{Nm} \mathrm{Mw}=8.34$

var. $=0.1820$
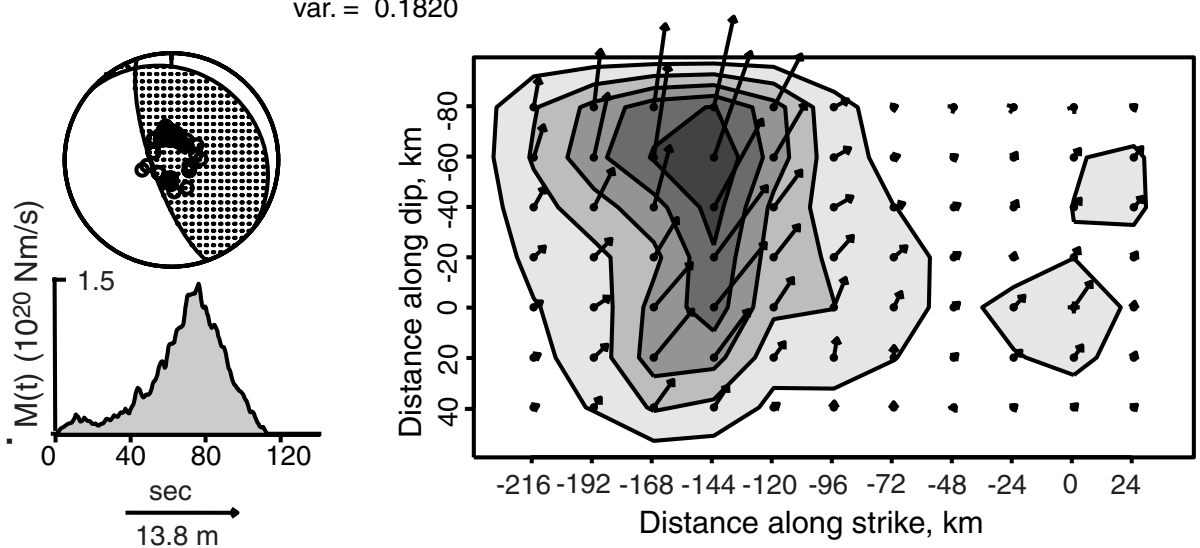

$\mathrm{Vr}=3.1 \mathrm{~km} / \mathrm{sec}$

$\mathrm{Mo}=3.9 \times 10^{21} \mathrm{Nm} \mathrm{Mw}=8.33$

var. $=0.1981$

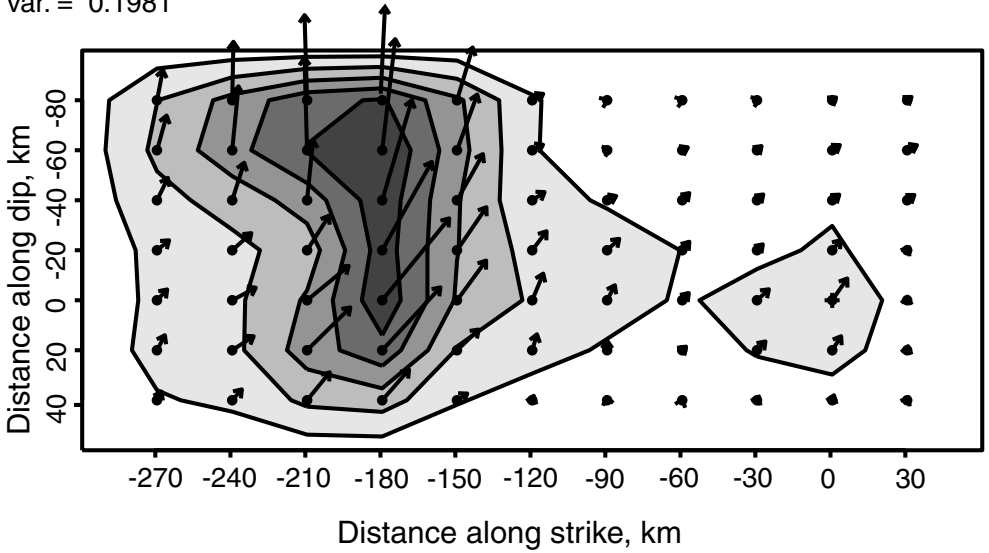

Figure 7. Finite-source models for the 2001 Peru earthquake from inversion of 46 teleseismic $P$ and $S H$ waves. Results for four different rupture velocities are shown, all with common spatial scales. The focal mechanism indicates the station distribution, and has a strike of $310^{\circ}$ and dip of $18^{\circ}$, which is the same for all solutions, and a rake of $60^{\circ}$, close to the average for all four solutions. The rake and total slip vector at each grid position are shown by the arrows. The hypocenter is located at $(0,0)$. In every case, the subfault source-time functions are parameterized with nine 4-sec duration triangles lagged by $2 \mathrm{sec}$ each, for maximum subfault rupture durations of $20 \mathrm{sec}$. The residual waveform mismatch variance (var.) is shown for each case, and is lowest for $V_{r}=2.5 \mathrm{~km} / \mathrm{sec}$. The along-strike grid spacing varies in proportion to the rupture velocity so that all models have similar duration moment rate functions, with the result for the $V_{r}=2.5 \mathrm{~km} / \mathrm{sec}$ inversion being shown. Waveform fits for the model with $V_{r} 2.5 \mathrm{~km} / \mathrm{sec}$ are shown in (E) Figure S2 in the electronic edition of BSSA; animation of the slip model can be viewed in (E) movie 6a,b in the electronic edition of BSSA. 
the near-source Earth structure. The solutions show a clear trade-off between rupture velocity and location of the large slip patch to the southeast relative to the small hypocentral slip patch. The teleseismic body-wave data simply do not uniquely resolve the spatial distribution of slip for these predominantly unilateral slip models. A rupture velocity of $\sim 2.5 \mathrm{~km} / \mathrm{sec}$ yields reasonable agreement with the relative location of the large slip patch to the southeast in the iterative deconvolution model, but while the slip in these slip-pulse models is distributed along isochrons, it is concentrated updip rather than down-dip. The waveform fits are significantly improved for these models relative to the iterative deconvolutions; over $80 \%$ of the signal power is fit. (E) Figure S2 in the electronic edition of BSSA shows comparisons of observed and synthetic waveforms for the $V_{r}=2.5 \mathrm{~km} / \mathrm{sec}$ case; an animation of the rupture expansion is available in movie 6. This particular model is very similar to the seismic inversion results presented by Kikuchi and Yamanaka (2001) and Pritchard et al. (2007), but it differs markedly from those of Robinson et al. (2006) and the back-projection images in Figure 3. While the slip-pulse models are sensible and the rupture history and final slip distribution are appealingly wellbehaved, it appears that in this case the imposition of strong kinematic constraints may be leading to either too low of an apparent rupture velocity and/or incorrect positioning of slip on the fault despite the excellent fit to the observations.

We next allowed the subfault rupture durations to extend much longer than conventional slip-pulse models, as an alternative to solving for a large range of rupture velocities in a given model. Our strategy is to still impose an upper bound on rupture velocity because that stabilizes the inversion relative to the iterative solution in Figure 6, while adding the model parameters required for long-duration subfault ruptures to allow the possibility of rerupture of subfaults, reversal of rupture duration, and delayed triggering effects. The duration of the subfault time functions effectively defines the time of a conceptual healing front that sweeps over the fault, trailing behind the rupture front and ceasing any further slip. Unlike a classic crack model, this expands from the hypocenter rather than propagating inward from the outermost edges of the crack, so it is close conceptually to the models with a wide range of rupture velocity values being allowed. With data segments of finite duration in time, the solution becomes unstable, particularly for total seismic moment, if the latest instance of slip on the fault occurs at or later than the end of the specified data interval. We explored many models with different subfault durations and triangle sequences and present representative solutions here.

Figure 8 shows models with the same rupture velocities as in Figure 7 , but subfault source-time functions now parameterized by 138 -sec duration triangles lagged by $4 \mathrm{sec}$ each, for total subfault rupture durations of $56 \mathrm{sec}$. Essentially, this means that every point on the fault can have variable time history of slip for that $56 \mathrm{sec}$, commencing with the first rupture front arrival. The overall slip distribution is still directly affected by the maximum rupture velocity imposed, but much broader areas of slip occur; all solutions indicate late slip occurring at distances less than $150 \mathrm{~km}$ from the hypocenter in contrast to the slip-pulse models in Figure 7. This persists for even higher rupture velocities. The total duration of the source function is about $140 \mathrm{sec}$, consistent with the R1 $T_{\text {avg }}$ estimate allowing for the broadening effects of filtering, but the moment estimates are almost twice as high, indicating instability in the moment estimates likely due to interference of signals from different parts of the fault, or some slip occurring late, outside the range of time wellconstrained by observations. The residual variance is about $10 \%$ for these models, with the added degrees of freedom in the space-time slip model enabling improved waveform matches relative to the slip-pulse models. The waveform matches for the $V_{r}=2.5 \mathrm{~km} / \mathrm{sec}$ case are shown in Figure 9a,b; it is clear that these models provide excellent matches to the complex signals. When even longer subfault durations of up to $92 \mathrm{sec}$ are allowed, the overall slip patterns are found to be stable, although the moment estimate grows systematically with total duration without much change in variance reduction (only a few percent better), indicating destructive interference in the late time components of the source model. Inversions that include only $P$ waves, but with 170 -sec long signal windows and very long subfault time function durations (up to $105 \mathrm{sec}$ ), give similar results, and no clear indication of significant slip after $130 \mathrm{sec}$.

The slip distributions in Figure 8 are very smooth; this is characteristic of all of the long-duration slip models that we considered. This contrasts with the irregular, patchy slip distribution estimated by the crack-type models of Robinson et al. (2006). An animation of the time-history of the rupture expansion (E) movie 7 in the electronic edition of BSSA) is provided; it is clear that there is significant irregularity in the slip history despite the smooth total slip distribution, so these models are essentially trading off temporal roughness with spatial roughness, whereas the opposite is manifested in the slip-pulse models. From the perspective of how the overall megathrust fails, there is strong appeal to the smoother final slip models, which, as discussed in the following paragraphs, agree well with geodetic models in terms of placement of slip.

The long-subfault slip-duration model for $V_{r}=$ $2.5 \mathrm{~km} / \mathrm{sec}$ was used to predict R1 source-time functions using a simplified procedure that ignores any intrarupture dispersion effects; the predictions are compared with the data in Figure 10. While details in the shapes of the signals are not matched, the overall range of duration is quite well matched; the fit is better than for the slip-pulse models, which predict strong unilateral effects even for low rupture velocities. It is possible to simultaneously invert the R1 source functions with the body-wave data (Ammon et al., 2008), or to impose a penalty function to stabilize the seismic moment estimate, but here we emphasize procedures that can be implemented rapidly without much a priori constraint; it is straightforward to perform the finite-source inversions assuming long 

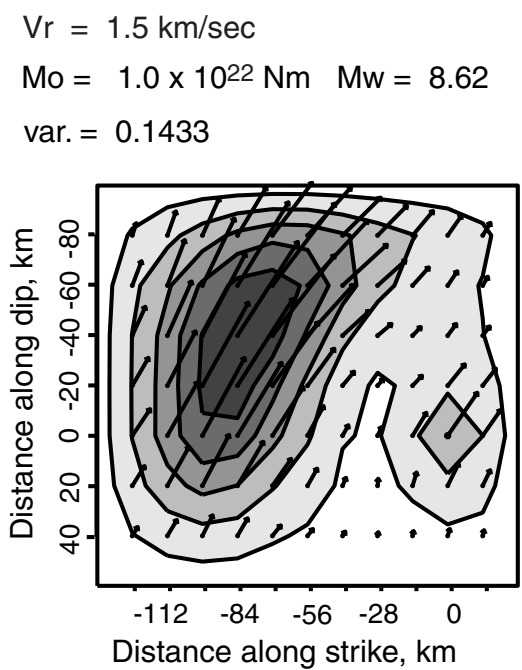

$\mathrm{Vr}=2.0 \mathrm{~km} / \mathrm{sec}$

$$
\begin{aligned}
& \text { Mo }=9.7 \times 10^{21} \mathrm{Nm} \mathrm{Mw}=8.59 \\
& \text { var. }=0.1200
\end{aligned}
$$

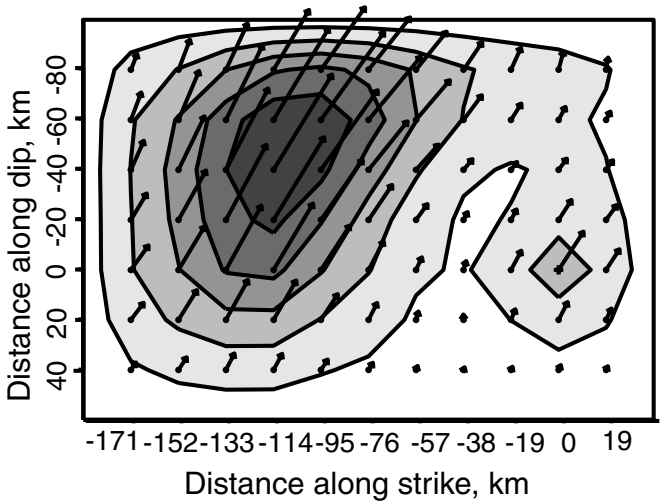

$$
\begin{aligned}
\mathrm{Vr} & =2.5 \mathrm{~km} / \mathrm{sec} \\
\mathrm{Mo} & =8.9 \times 10^{21} \mathrm{Nm} \quad \mathrm{Mw}=8.57 \\
\text { var. }= & 0.1075
\end{aligned}
$$
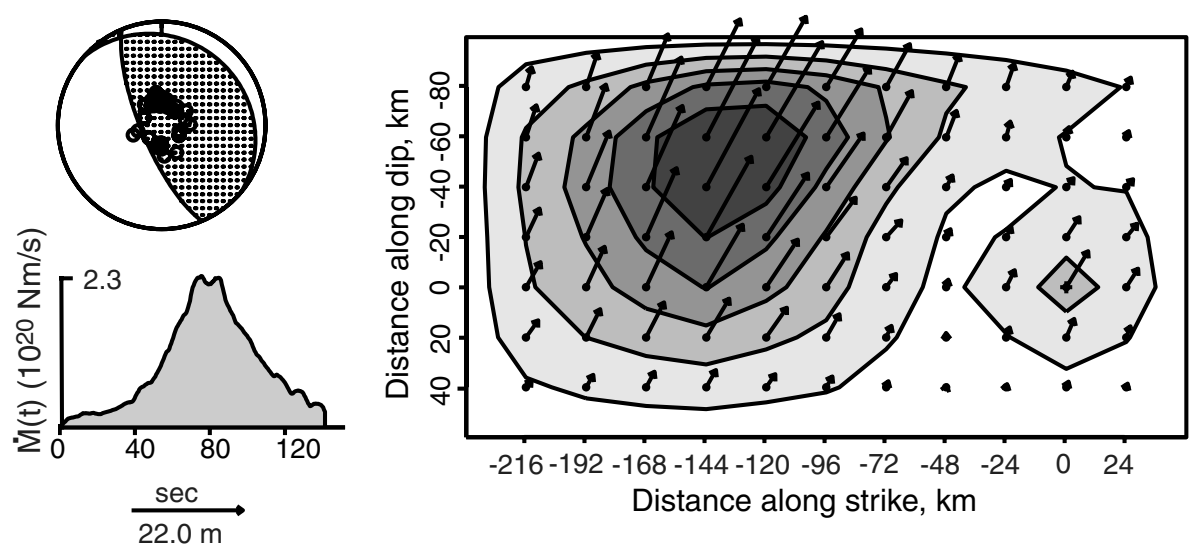

$\mathrm{Vr}=3.1 \mathrm{~km} / \mathrm{sec}$

var. $=0.1058$

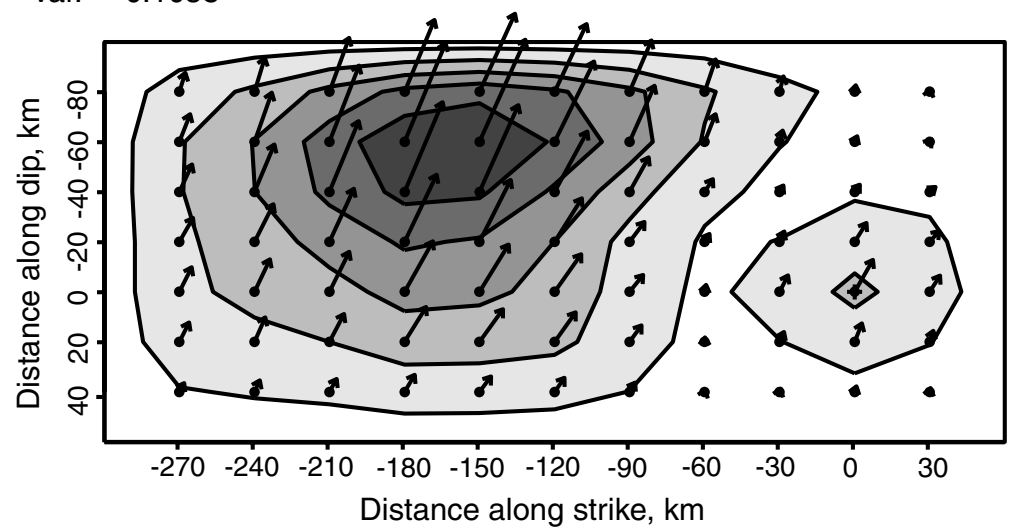

Figure 8. Finite-source models for the 2001 Peru earthquake from inversion of 46 teleseismic $P$ and $S H$ waves. Results for four different rupture velocities are shown, all with common spatial scales. The focal mechanism indicates the station distribution, and has a strike of $310^{\circ}$ and dip of $18^{\circ}$, which is the same for all solutions, and a rake of $60^{\circ}$, close to the average for all four solutions. The rake and total slip vector at each grid position are shown by the arrows. In every case, the subfault source-time functions are parameterized with 138 -sec duration triangles lagged by $4 \mathrm{sec}$ each, for maximum subfault rupture durations of $56 \mathrm{sec}$. The residual waveform mismatch variance (var.) is shown for each case. The along-strike grid spacing varies in proportion to the rupture velocity so that all models have similar duration moment rate functions, with the result for the $V_{r}=2.5 \mathrm{~km} / \mathrm{sec}$ inversion being shown. Corresponding waveform fits are shown in Figure 9. Animations of $V_{r}=2.5 \mathrm{~km} / \mathrm{sec}$ rupture sequence can be viewed in (E) movie 7a,b in the electronic edition of BSSA.

subfault rupture durations to characterize whether the inferred slip distribution differs from a slip-pulse behavior.

The 2001 event clearly begins as a modest size rupture during the first $30-40 \mathrm{sec}$. It is not clear whether the fault was sliding continuously after the first $10 \mathrm{sec}$, or whether it was a discrete event located near the hypocenter that triggered a larger secondary event. The latter appears viable, and even likely, given the high apparent rupture velocity $\left(V_{r} \sim 3 \mathrm{~km} / \mathrm{sec}\right)$ implied by the 50 -sec feature in the $P$-wave back-projection image (Fig. 3). This is relevant for finitesource inversions, because they are kinematically constrained to grow from an initial hypocenter (with an expanding circular zone of activated subfaults). If the event is a compound earthquake doublet, the onset of the second event should allow circular expansion of the rupture from its hypocenter, rather than having the late rupture constrained to isochrons defined by the initial hypocenter. This allows slip, even for a slip-pulse model, to occur back toward the initial event. Given the apparent need for slip to occur later than $50 \mathrm{sec}$ in the region between the initial hypocenter and the main pulse $\sim 120-150 \mathrm{~km}$ away, we inverted the 46 body waves for two events separated by $37 \mathrm{sec}$ in time and with hypocenters separated by $120 \mathrm{~km}$ along strike. The specific lag time of $37 \mathrm{sec}$ was chosen based on aligning the onset of strong secondary arrivals in the waveforms. We specified a normal $V_{r}=3.11 \mathrm{~km} / \mathrm{sec}$ for the first event and a slower $V_{r}=2.0 \mathrm{~km} / \mathrm{sec}$ for the second, motivated by the back-projection images. Event 1 had four 4-sec duration 
(a)

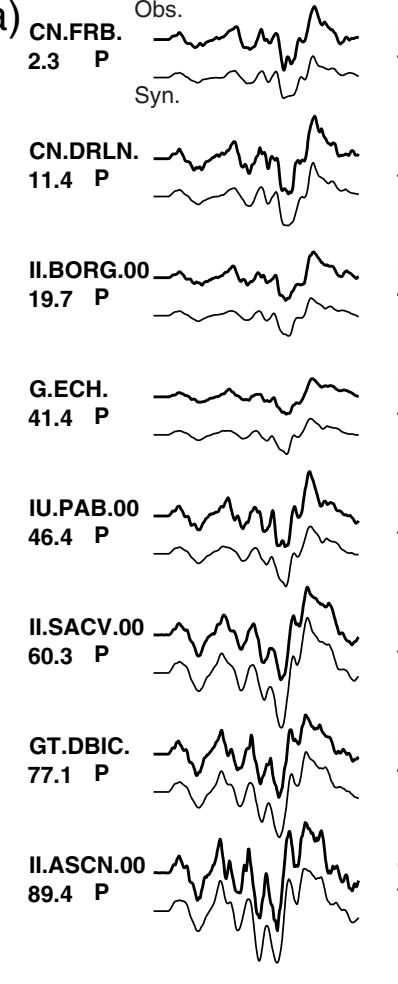

(b)

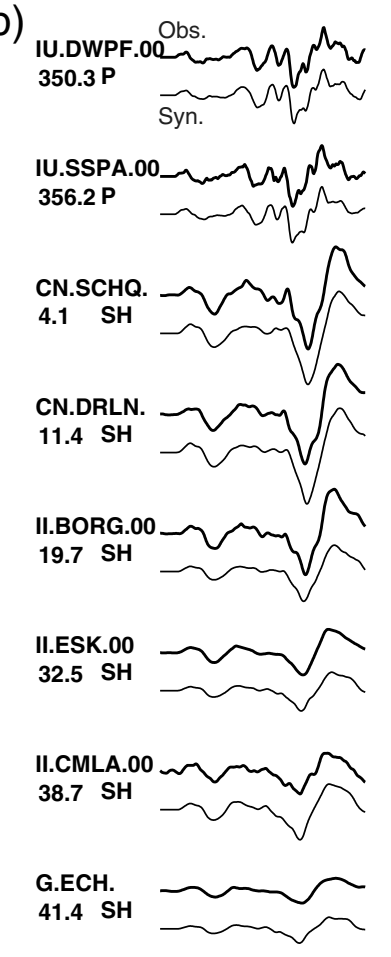

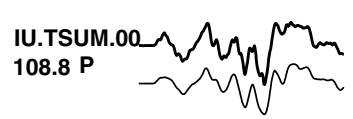

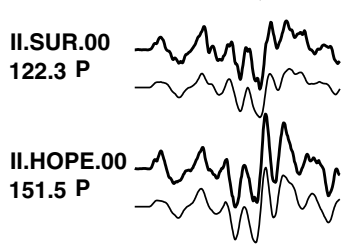

IU.PMSA.00_Lm P

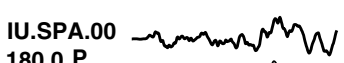

180.0 P

IU.CASY.00__ 181.7 P
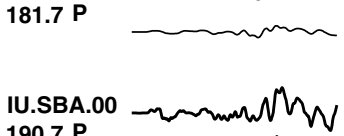

190.7 P

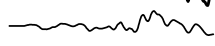

G.DRV.00 $192.7 \mathrm{P}$
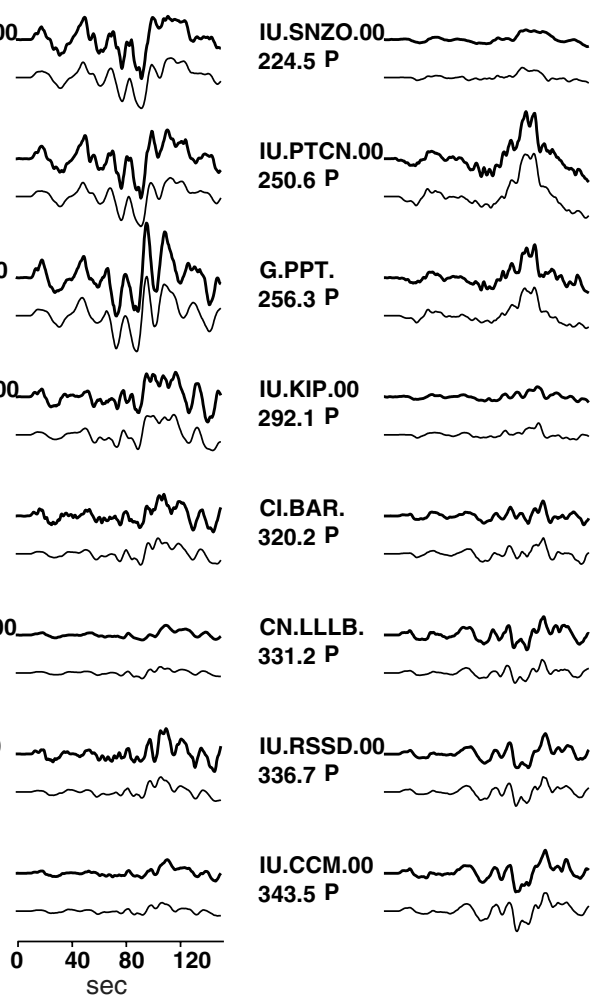

IU.KIP.00

292.1 P

CI.BAR. רuntur $320.2 \mathrm{P}$

CN.LLLB. حns $331.2 \mathrm{P}$

IU.RSSD.00_unch $336.7 \mathrm{P}$

IU.CCM.00 Mnsm $343.5 \mathrm{P}$
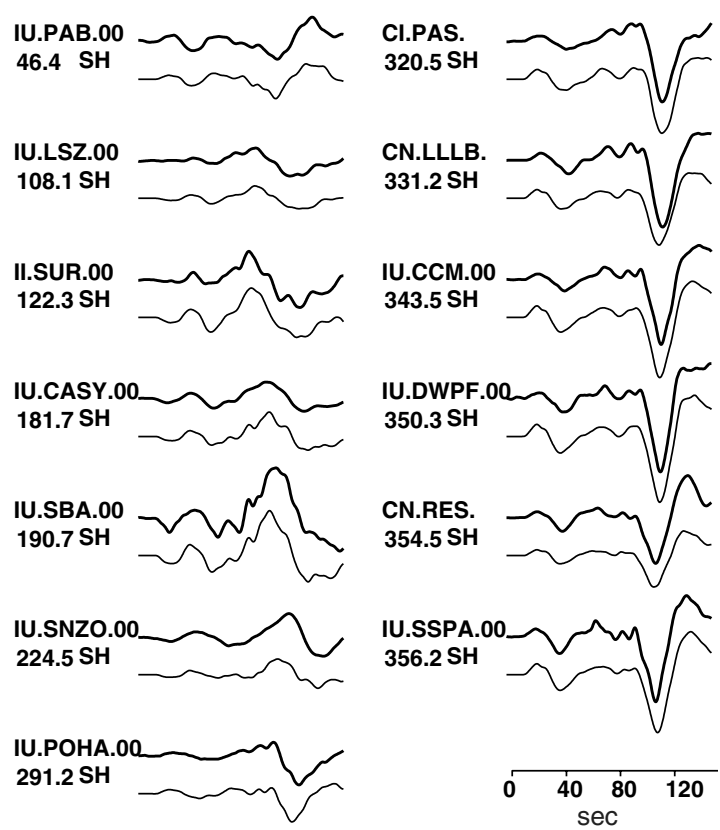

IU.KIP.00

$292.1 \mathrm{SH}$

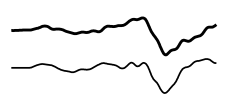

Figure 9. (a, b) Observed (upper bold lines in each pair) and synthetic (lower thin lines in each pair) teleseismic $P$ and $S H$ waves for the 2001 Peru event for the preferred long-subfault rupture duration model with a rupture velocity of $2.5 \mathrm{~km} / \mathrm{sec}$ and subfault source durations of $56 \mathrm{sec}$ (Fig. 8). The azimuth of each broadband displacement trace (filtered in the passband $0.005-0.9 \mathrm{~Hz}$ ) is indicated below the station code. Amplitudes for $S H$ waves are on $1 / 5$ scale relative to $P$ waves. 


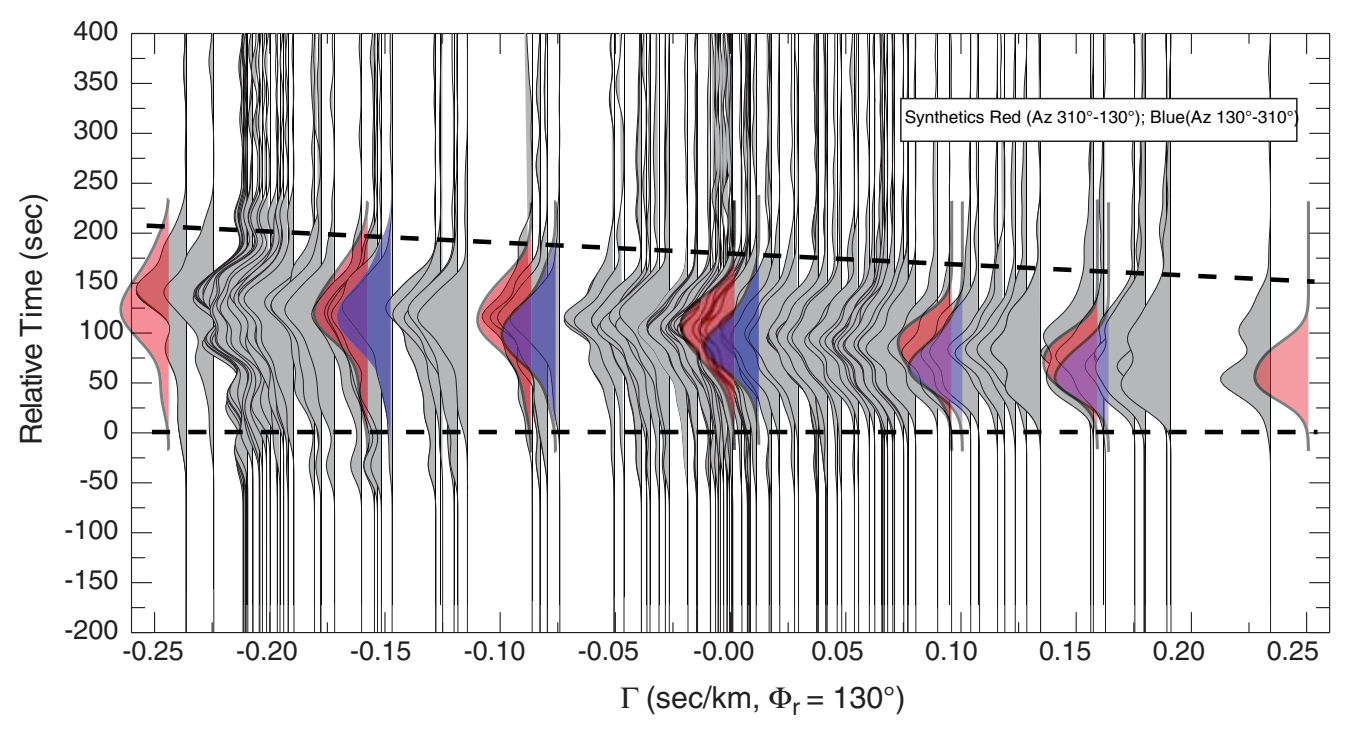

Figure 10. Comparison of observed and predicted R1 effective source-time functions for the 2001 Peru event for the rupture model shown in Figure 8 with $V_{r}=2.5 \mathrm{~km} / \mathrm{sec}$. The red and blue traces are synthetics distinguished by azimuth relative to the average rupture direction of $130^{\circ}$ (red traces are azimuths to the northeast range and blue are azimuths to the southwest). Both data and synthetics have been convolved with a Gaussian filter with averaging width 0.05 . The model matches the overall variation in duration of the R1 observations.

triangles lagged by $2 \mathrm{sec}$ each, and Event 2 had nine 4-sec duration triangles lagged by 2 sec each, with each event having slip-pulse-type rupture expanding from their hypocenter. Figure 11 shows the resulting composite slip model, with the first event slip and source function being highlighted in red. Event 1 has $M_{0} 2.3 \times 10^{20} \mathrm{Nm}$, and Event 2 has $M_{0} 4.2 \times 10^{21} \mathrm{Nm}$. Waveform comparisons are shown in (E) Figure S3 and the rupture animation is in movie 8 in the electronic edition of BSSA. This model, like the long-subfault slip-duration model (the solution for $V_{r}=2.5 \mathrm{~km} / \mathrm{sec}$ from Fig. 8 is shown in the middle row), does allow significant slip to be located within $100 \mathrm{~km}$ of the initial hypocenter, unlike the single slip-pulse inversion (the corresponding solution for $V_{r}=2.5 \mathrm{~km} / \mathrm{sec}$ from Fig. 7 is shown at the bottom). With the spatial and temporal delay between the two events not being uniquely defined but generally being close to the Rayleigh wave velocity, we prefer the compound model for this event because it has a slip distribution in general agreement with the iterative and back-projection results while retaining intuitively appealing kinematic structure and a total seismic moment close to long-period estimates. However, from the rapid analysis perspective, the long-subfault slipduration parameterization, simply rescaled to match longperiod estimates of the seismic moment, provides an equally good basic assessment of relative slip distribution on the fault.

\section{Peru Earthquake}

The Global CMT solution (Ekström, 2009) for the 2007 Peru event has a best double couple with $\phi=321^{\circ}, \delta=28^{\circ}$, $\lambda=63^{\circ}$, while Biggs et al. (2009) recalculate a CMT solution with $\phi=324^{\circ}, \delta=22^{\circ}, \lambda=70^{\circ}$. The USGS hypocentral depth estimate is $39 \mathrm{~km}$. Based on our modeling of $P$ waves, we prefer the shallower dip and settle on a fault geometry with $\phi=324^{\circ}, \delta=22^{\circ}, \lambda=70^{\circ}$, and hypocentral depth of $39 \mathrm{~km}$ for all of our modeling.

Global Seismic Network and EarthScope Transportable Array surface wave recordings for the 2007 earthquake were processed as previously stated, with the R1 effective sourcetime functions being characterized by two dominant pulses, which have only a few tens of seconds of azimuthal relative variation in timing. The differential times between the pulse peaks were measured and used in a standard unilateral directivity analysis, in which all possible rupture azimuths were considered, with the data being plotted as functions of associated directivity parameters and regression of the differential times versus directivity parameter performed. Based on the correlation coefficients for each regression, a preferred rupture azimuth of $205^{\circ}$ (oblique to the trend of the trench), was clearly preferred, as shown in Figure 12. When the source functions are plotted versus directivity parameter for this rupture direction, they exhibit smoothly changing total durations and shifts between the two main subevents, as shown in Figure 13. In this case, the Gaussian averaging parameter was 0.1 , which suppresses periods shorter than $\sim 25 \mathrm{sec}$; the onsets of the source functions are well enough defined that they can be aligned quite well relative to each other (improving on the alignments from the aspherical phase velocity model corrections).

Extrapolating trends across all the data gives estimates of maximum duration, $T_{\max } \sim 160 \mathrm{sec}$, minimum duration, $T_{\min } \sim 125 \mathrm{sec}$, and average duration, $T_{\text {avg }} \sim 143 \mathrm{sec}$. The differential values have lower uncertainty than for the 2001 event, on the order of $\pm 10 \mathrm{sec}$, with all durations being broadened by about $30 \mathrm{sec}$ due to the filtering. For a simple unilateral rupture model, we obtain $L \sim 70 \mathrm{~km}$. For zero rise time, we get $V_{r} \sim 0.6 \mathrm{~km} / \mathrm{sec}$, as a lower bound. For $\tau=$ 
(a)

Two Events

$\mathrm{Mo}=2.3 \times 10^{20} \mathrm{Nm}, \quad \mathrm{Mw}=7.5$

$\mathrm{h}=29.6 \mathrm{~km}$, var. $=0.1280$

4 Triangles $\mathrm{T} 1=2, \mathrm{~T} 2=4, \mathrm{Vr}=3.11 \mathrm{~km} / \mathrm{sec}$

$\mathrm{Mo}=4.2 \times 10^{21} \mathrm{Nm}, \quad \mathrm{Mw}=8.4$

$\mathrm{h}=29.6 \mathrm{~km}$, var. $=0.1410$

9 Triangles $\mathrm{T} 1=2, \mathrm{~T} 2=4$, Delay $37 \mathrm{~s}, \mathrm{Vr}=2.0 \mathrm{~km} / \mathrm{sec}$
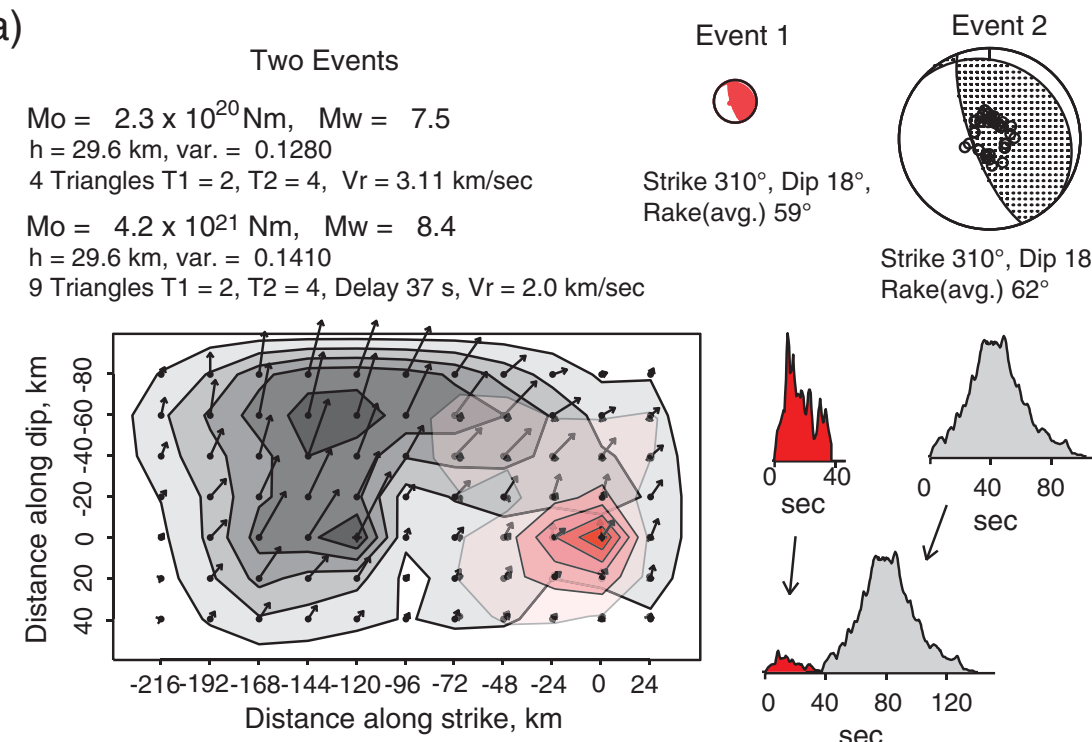

Strike $310^{\circ}$, Dip $18^{\circ}$ Rake(avg.) $62^{\circ}$

(b)

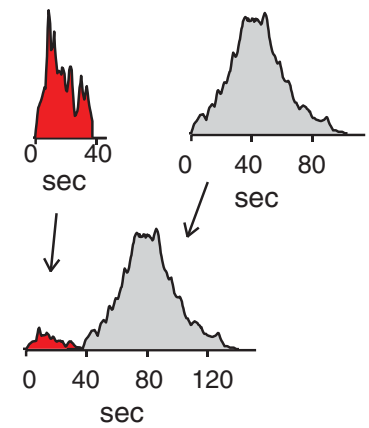

S) Simultaneous, $\mathrm{Vr}=2.5 \mathrm{~km} / \mathrm{sec}$

$\mathrm{Mo}=8.9 \times 10^{21} \mathrm{Nm}, \mathrm{Mw}=8.6$

$\mathrm{h}=29.6 \mathrm{~km}$, var. $=0.1075$

13 Triangles $\mathrm{T} 1=4, \mathrm{~T} 2=8$
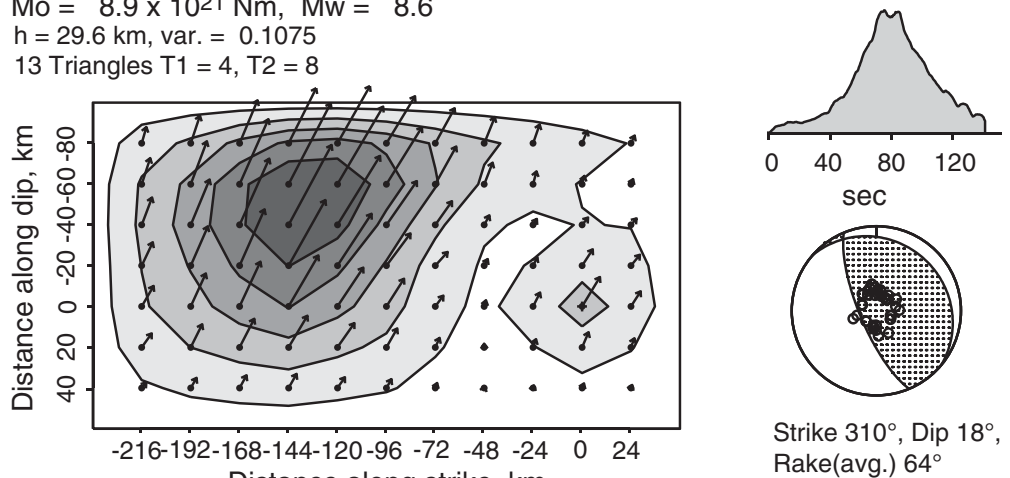

Strike $310^{\circ}$, Dip $18^{\circ}$ Rake(avg.) $64^{\circ}$

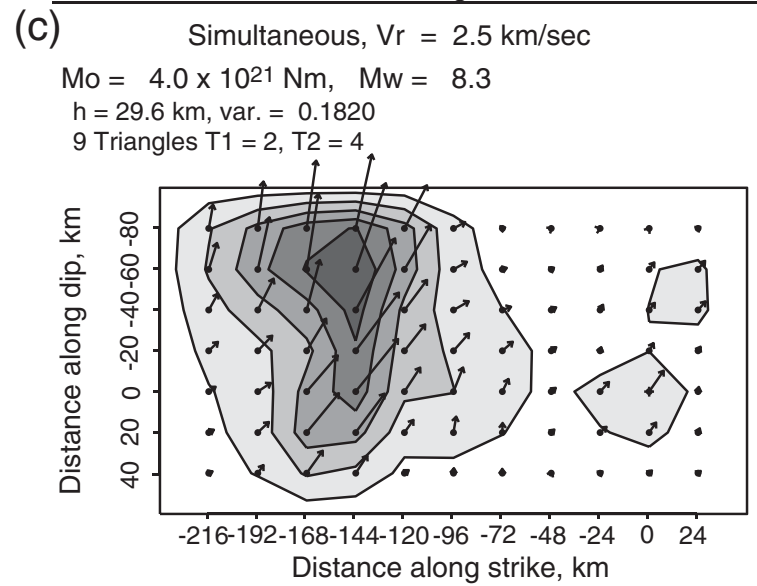

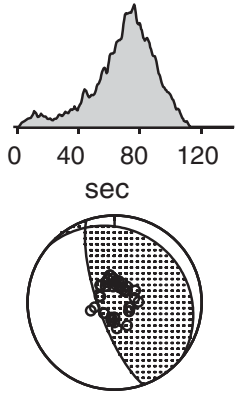

Strike $310^{\circ}$, Dip $18^{\circ}$, Rake(avg.) $60^{\circ}$

Figure 11. Two-event composite rupture model for the 2001 Peru earthquake. The event was treated like a double earthquake, with events 1 and 2 separated by $37 \mathrm{sec}$ in time and with hypocenters separated by $120 \mathrm{~km}$ along strike. The rupture velocity was $3.11 \mathrm{~km} / \mathrm{sec}$ for the first event and $2.0 \mathrm{~km} / \mathrm{sec}$ for the second. Event 1 had four 4-sec duration triangles lagged by $2 \mathrm{sec}$ each, and the second event had nine 4-sec duration triangles lagged by 2 sec each. Forty-six teleseismic $P$ and $S H$ waves were inverted for the slip functions of each event (a: left) with associated focal mechanisms and source-time functions (a: right), with the first event being highlighted in red. The slip models and time functions for single rupture models with $V_{r}=2.5 \mathrm{~km} / \mathrm{sec}$ from Figures 8 and 7 are shown in (b) and (c), respectively. Waveform fits for the composite model are shown in (E) Figure S3 in the electronic edition of BSSA; animation of the slip model can be viewed in (E) movie 8a,b in the electronic edition of BSSA. 


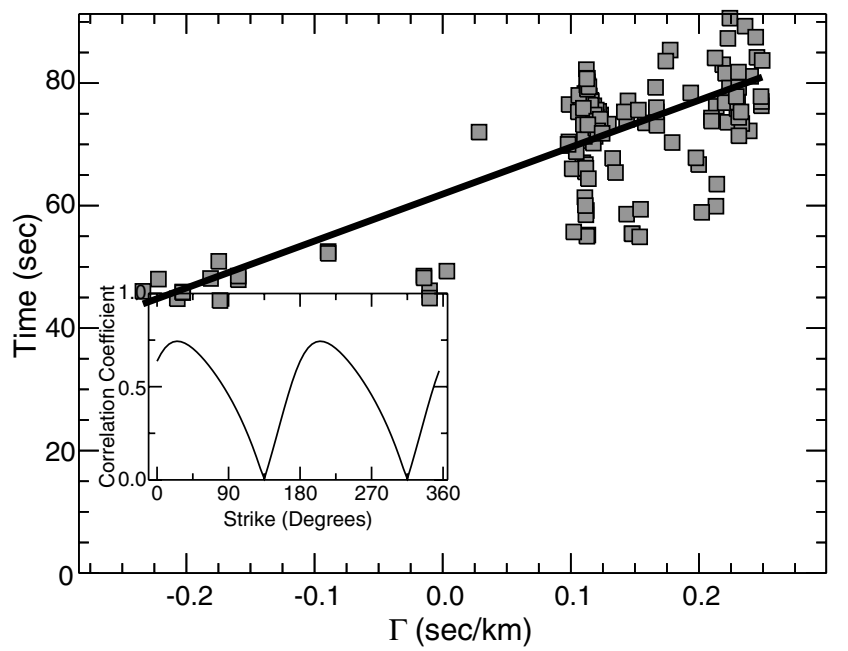

Figure 12. Directivity analysis based on the time between the two main peaks in the effective Rayleigh wave (R1) source-time functions for the 2007 Peru event (see Fig. 13) obtained by iteratively deconvolving point-source synthetics computed for a double couple with strike $324^{\circ}$, dip $22^{\circ}$, rake $70^{\circ}$, and depth of $39 \mathrm{~km}$ from the data using a positivity constraint. The peak correlation coefficient found for regressions for all possible unilateral rupture directions (inset) indicates an optimal unilateral azimuth of $205^{\circ}$, for which the specific regression is shown.

$0.10 T_{\text {avg }}$, we get $V_{r} \sim 0.7 \mathrm{~km} / \mathrm{sec}$. These rupture velocity estimates are again quite low, indicating that either the event was a slow rupture or that the assumption of unilateral rupture is incorrect. We again believe that the latter is the correct explanation, and infer from the R1 signals that this event has a very spatially compact source, as suggested by previous analyses.

Our teleseismic broadband body-wave data set for this event involves $30 \mathrm{P}$ waves and $20 \mathrm{SH}$ waves with good azimuthal distribution. The signal windows were 137-sec long from the origin time, again bounded mainly by avoiding large $S c S$ arrivals from strong secondary pulses in the source functions. We apply the four different styles of finite-source inversions discussed for the 2001 event to the 2007 event data set.

An iterative deconvolution for the 2007 Peru event is shown in Figure 14, where 40 subevents having symmetric triangular source functions (5-sec rise, 5-sec fall) on a grid of point-sources with the fixed fault orientation listed previously were obtained from the 50 teleseismic body waves. A causality rupture velocity bound of $3.11 \mathrm{~km} / \mathrm{sec}$ was assumed, which is in line with a rough estimation of the rupture velocity for the main slip patch in the back-projection results shown in Figure 4. The fault dimensions were kept compact, guided by the back-projection and R1 directivity results. The fault-normal source-time function shown in the figure has two basic subevents separated by $60 \mathrm{sec}$ in time, with total $M_{0} 1.1 \times 10^{21} \mathrm{Nm}$. The larger secondary pulse is associated with a patch of subevents from 30 to $60 \mathrm{~km}$ to the southeast from the $39 \mathrm{~km}$ deep hypocenter, and the overall rupture velocity is about $0.8-1.0 \mathrm{~km} / \mathrm{sec}$. The waveform mismatch (residual power scaled by the signal power) for this model is 0.22 , significantly better than for the 2001 event. Waveform fits for the model in Figure 14 are shown in (E) Figure S4 in the electronic edition of BSSA.

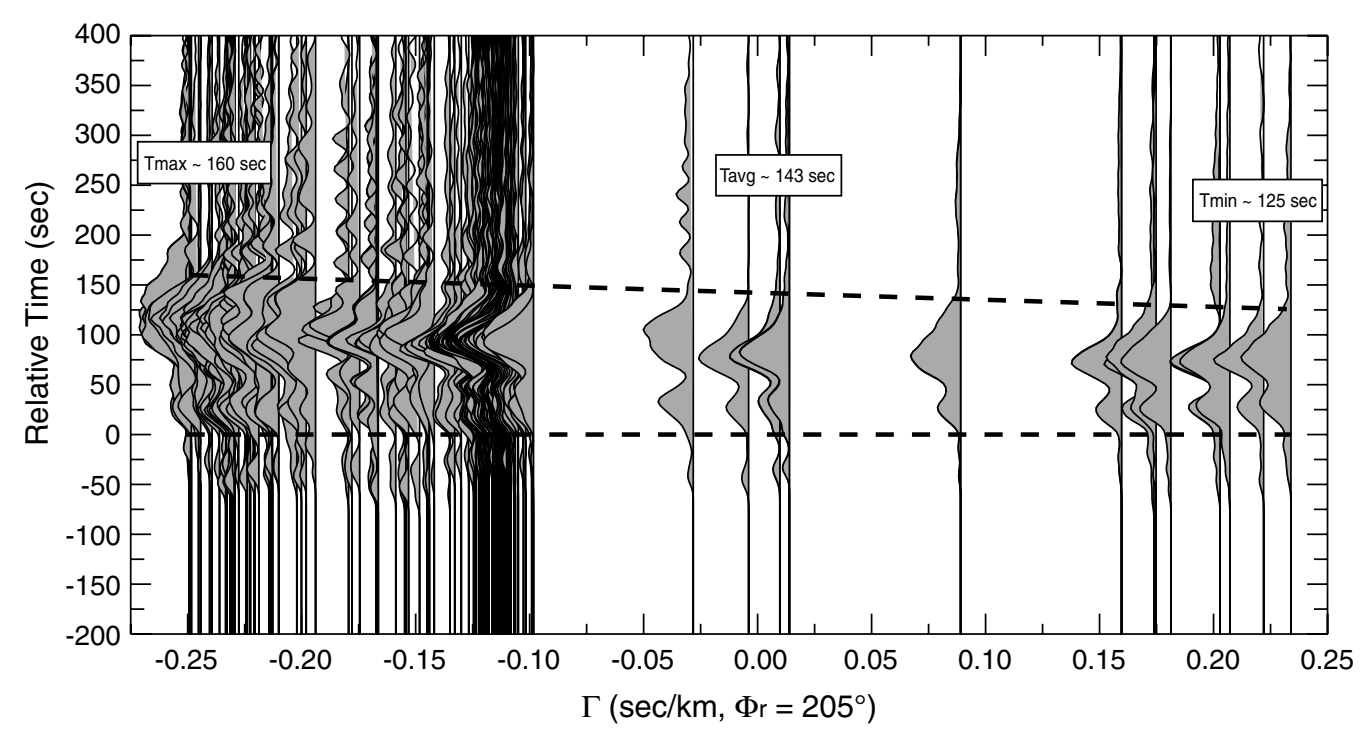

Figure 13. Effective Rayleigh wave (R1) source-time functions for the 2007 Peru event obtained by iteratively deconvolving pointsource synthetics computed for a double couple with strike $324^{\circ}$, dip $22^{\circ}$, rake $70^{\circ}$, and depth of $39 \mathrm{~km}$ from the data using a positivity constraint. The synthetics for the PREM structure were corrected for aspherical phase velocity heterogeneity. Minor onset misalignments were adjusted by aligning zero intercepts of tangents to the first pulse slope. The source functions are plotted as a function of the directivity parameter, assuming a rupture azimuth of $205^{\circ}$, as indicated by the directivity analysis in Figure 12 . For a reference phase velocity of $4.0 \mathrm{~km} / \mathrm{sec}$, the estimated $T_{\max } \sim 160 \mathrm{sec}, T_{\min } \sim 125 \mathrm{sec}$. The estimated $T_{\mathrm{avg}} \sim 143 \mathrm{sec}$. The duration measures are all increased by $\sim 30 \mathrm{sec}$ by the Gaussian filter. 


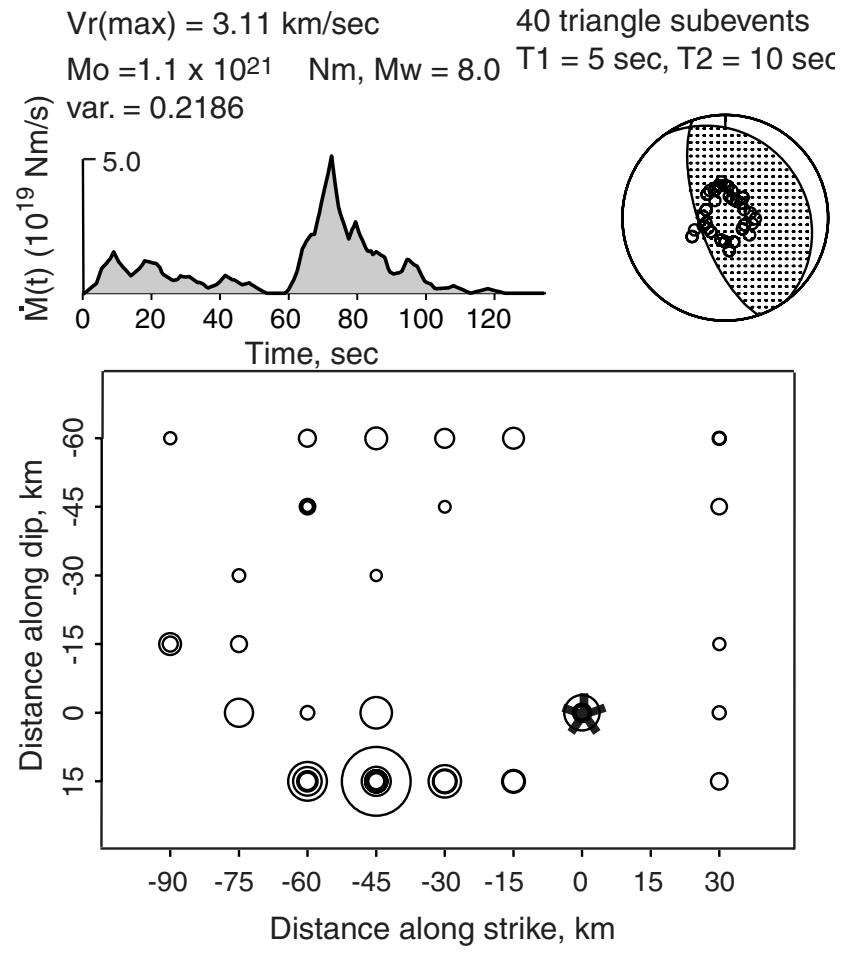

Figure 14. Spatial distribution of subevents for the 2007 Peru earthquake rupture obtained by iterative deconvolution of 50 teleseismic $P$ and $S H$ waves. Forty subevents with triangle source-time functions with 5-sec rise-time (T1), and 10-sec durations (T2) were solved for. The focal mechanism shown was fixed for all subevents and has strike $324^{\circ}$, dip $22^{\circ}$, and rake $70^{\circ}$. The lower hemisphere projection of the station distribution is shown in the focal mechanism. The hypocentral depth was $39 \mathrm{~km}$. The residual variance in the waveform misfit (var.) was 0.22 after 40 iterations. The asterisk indicates the hypocenter and circles are scaled proportional to the subevent seismic moments. The fault-normal far-field source-time function for the composite sequence is indicated at the top left, and was constrained to have a maximum duration of $120 \mathrm{sec}$. Waveform fits for this model are shown in (E) Figure S4 in the electronic edition of BSSA.

Similar inversion results were obtained for different subevent source functions with triangular and trapezoidal shapes. We basically infer only that there was a large slip patch at a distance of $\sim 45-60 \mathrm{~km}$ from the hypocenter from 60 to $80 \mathrm{sec}$ into the rupture. The back-projection result suggests that high-frequency energy radiated from $\sim 50 \mathrm{~km}$ south-southeast of hypocenter $\sim 60 \mathrm{sec}$ after the rupture onset (Fig. 4), but the time sequence of later subevents in the iterative deconvolution is again not considered sufficiently stable to infer further details of the later rupture.

Slip-pulse type inversions for the 2007 Peru event were performed for rupture velocities ranging from 0.5 to $3.11 \mathrm{~km} / \mathrm{sec}$. Only very low rupture velocities $\left(V_{r}<\right.$ $1 \mathrm{~km} / \mathrm{sec}$ ) can match the compact source dimensions indicated by the back projections, R1 source-time functions, and iterative inversions. Results for $V_{r}=0.9 \mathrm{~km} / \mathrm{sec}$ are shown in Figure 15. The subfault source-time functions were parameterized with five 5-sec duration triangles with variable moment lagged by $2.5 \mathrm{sec}$ each, for maximum subfault durations of $12.5 \mathrm{sec}$. The overall source-time function has the two-event characteristic in common with all inversions, with $60 \mathrm{sec}$ between their onsets and a total duration of $\sim 120 \mathrm{sec}$, in reasonable agreement with the R1 estimated average duration. The lack of spatial directivity of the solution leads to slip being smeared over the rupture isochron for the slip-pulse models; when more extended rupture surfaces are allowed, slip tends to be nonuniformly distributed over a full circle around the hypocenter. There is an enhancement of slip up-dip and to the southwest, so there is a degree of spatial resolution, but the overall pattern of model slip for this event is strongly influenced by the prescribed fault dimensions and rupture velocity. (E) Figure S5 in the electronic edition of BSSA shows comparisons of the observed and synthetic waveforms for the $V_{r}=0.9 \mathrm{~km} / \mathrm{sec}$ case, with more than $86 \%$ of the waveform power accounted for by the slippulse model. An animation of the rupture expansion is available (E) movie 9 in the electronic edition of BSSA). This particular model is similar to the slip-pulse type seismic inversions presented by Ji and Zeng (2007), Yagi (2007), Yamanaka (2007), Pritchard and Fielding (2008), and Sladen et al. (2010), but it differs markedly from the crack-type solution of Biggs et al. (2009) and the back-projection images in Figure 4, so the situation is basically similar to that for the 2001 event; we explore more flexible rupture parameterization with longer subfault source functions that allow slip to have more complex time variations at each grid point.

Figure 16 shows models sharing a rupture velocity of $3.11 \mathrm{~km} / \mathrm{sec}$, but having subfault dimensions that vary from $15 \mathrm{~km} \times 15 \mathrm{~km}$ to $30 \mathrm{~km} \times 30 \mathrm{~km}$. The purpose is to assess whether the body-wave data resolve the overall spatial finiteness or not. The subfault source-time functions are parameterized by 227 -sec duration triangles lagged by $3.5 \mathrm{sec}$ each, for total subfault rupture durations of $80.5 \mathrm{sec}$. This is long enough that it would be possible for the second large source to colocate with the hypocenter, but it always locates up-dip and along strike. The source-time functions are similar for these models, as are the average rake values for each case. The best variance reduction is for the $20 \mathrm{~km} \times 20 \mathrm{~km}$ case, but the best consistency with the constraints on rupture compactness is for the $15 \mathrm{~km} \times 15 \mathrm{~km}$ case. This is illustrated in Figure 17, which superimposes a vector corresponding to the unilateral directivity estimated from the R1 source-time functions on the dip-corrected slip map for the $15 \mathrm{~km} \times 15 \mathrm{~km}$ case. The $70 \mathrm{~km}$ length estimated from R1 STF directivity is well matched by the slip model. We note that the $20 \mathrm{~km} \times 20 \mathrm{~km}$ solution does not do badly, but larger fault dimensions are at odds with the R1 results. The final slip distributions are quite smooth relative to the slip-pulse model in Figure 15, but the seismic moments are larger than long-period estimates by factors of 2 to 3 , indicating some instability in the long-period components of the source function. The total duration of the source function is about $120 \mathrm{sec}$. The residual variance is about $10 \%$ for these models, somewhat improved relative to the slip-pulse-type models. 


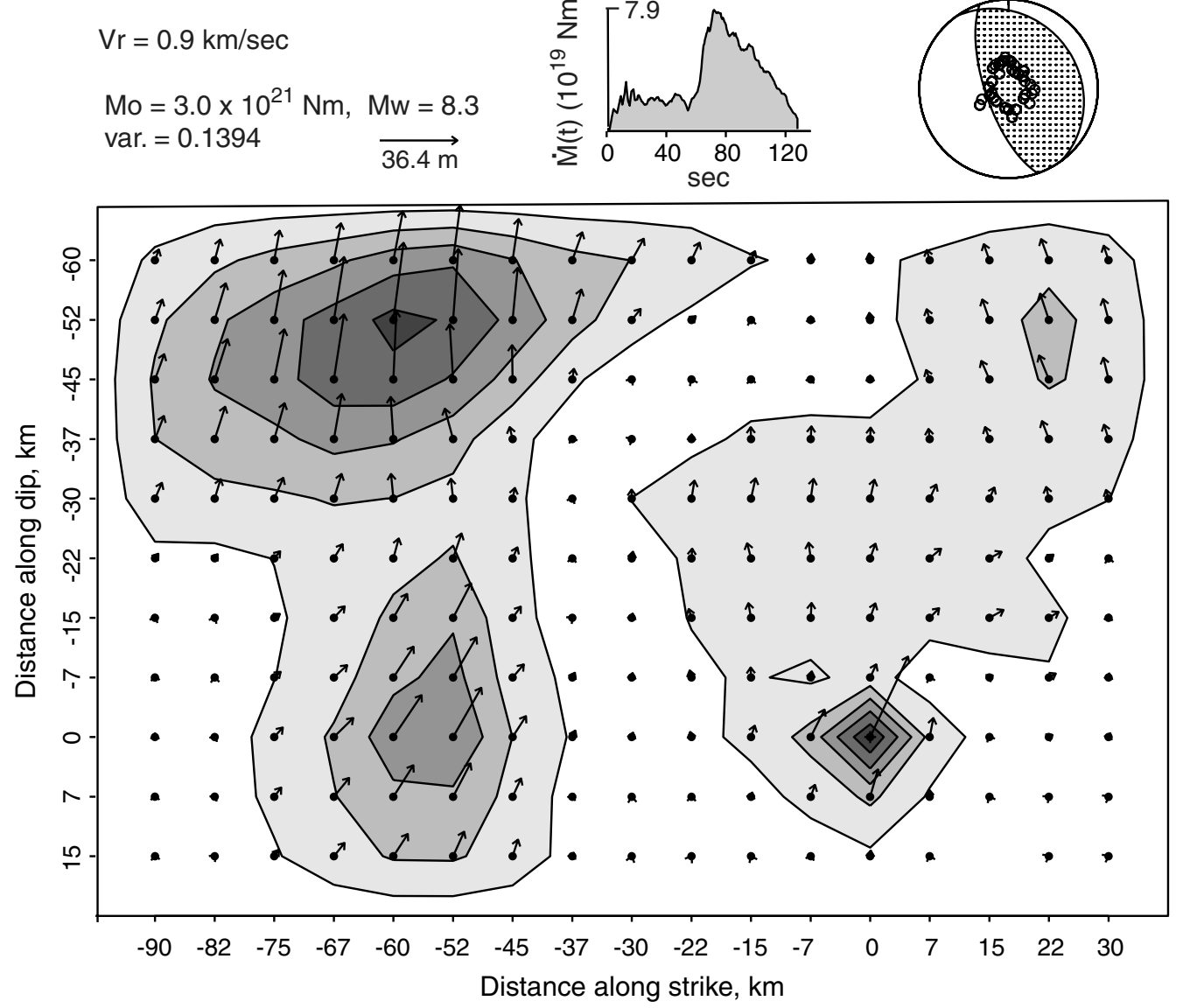

Figure 15. Finite-source model for the 2007 Peru earthquake from inversion of 50 teleseismic $P$ and $S H$ waves. A rupture velocity of $0.9 \mathrm{~km} / \mathrm{sec}$ was assumed. The focal mechanism indicates the station distribution, and has $\phi=324^{\circ}, \delta=22^{\circ}$, and $\lambda=74^{\circ}$. The hypocentral depth was $39 \mathrm{~km}$. The rake and total slip vector at each grid position are shown by the arrows. The subfault source-time functions are parameterized with five 2.5 -sec duration triangles lagged by $2.5 \mathrm{sec}$ each, for maximum subfault rupture durations of $15 \mathrm{sec}$. The residual waveform mismatch variance (var.) is 0.14 . The total rupture duration is about $130 \mathrm{sec}$. Waveform fits for the slip-pulse model are shown in (E) Figure S5 in the electronic edition of BSSA; animation of the slip model can be viewed in (E) movie 9a,b in the electronic edition of BSSA.

The observed and synthetic waveforms for the $15 \mathrm{~km} \times$ $15 \mathrm{~km}$ subfault source model in Figure 17 are compared in Figure 18a,b. (E) Movie 10 in the electronic edition of BSSA shows an animation of the time-history of the rupture expansion. The waveform fit is very good. The animation again makes it clear that there is irregularity in the slip history despite the smooth total slip distribution, so these models also trade off roughness of the temporal history with roughness of the spatial distribution in a fashion complementary to the slip-pulse type models.

The long-subfault slip-duration model for the $15 \mathrm{~km} \times$ $15 \mathrm{~km}$ subfault dimensions was used to predict R1 sourcetime functions, and the predictions are compared with the data in Figure 19. In this case, the shapes of the R1 source functions are quite well reproduced, as is the overall azimuthal range of duration, and the fit improves slightly on that obtained for the slip-pulse-type models. Thus, while the overall moment (and absolute slip vectors) appear to be overestimated by a factor of $\sim 2$, the spatial pattern of slip appears reasonable.
One of the key questions raised by the rupture models in Figures 14, 15, and 16 is whether the 2007 event involves continuous rupture or triggering of a secondary event with some delay after waves from an initial event pass by. The uncertainty in the long-period baseline for the long-subfault slipduration models makes it unclear whether the source radiation dropped off as in Figure 14 or not. The EarthScope Transportable Array (TA) was favorably located along the trench strike azimuth during the 2007 event, and a large number of clear $S H$ waves were recorded by the TA. We aligned and linearly stacked these ground displacement data to enhance the signal-to-noise ratio between the two subevents, which are clearly manifested in the SH waveforms. Figure 20 shows the stack for TA stations at epicentral distances less than $65^{\circ}$ away, for which $S c S$ from the first event is not in the time interval between the sec arrivals from the two subevents. There is very little ground displacement between the subevents, suggesting that if there was continuous rupture, little slip occurred, the focal mechanism was different, or the slip had very long rise-time so that intermediate period 
$\mathrm{Vr}=3.11 \mathrm{~km} / \mathrm{sec}, 15 \mathrm{~km} \times 15 \mathrm{~km}$

Mo $=2.2 \times 10^{21} \mathrm{Nm}, \mathrm{Mw}=8.2$

var. $=0.1177$

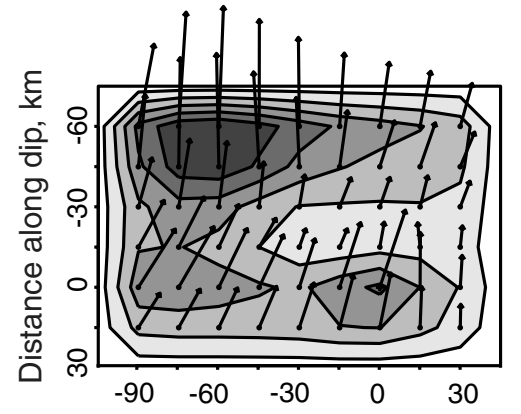

Distance along strike, $\mathrm{km}$
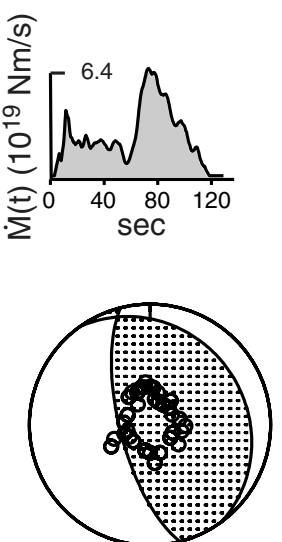

Strike $=324^{\circ}$

Dip $=22^{\circ}$

Rake(avg.) $=77^{\circ}$
$\mathrm{Vr}=3.11 \mathrm{~km} / \mathrm{sec}, 25 \mathrm{~km} \times 25 \mathrm{~km}$

$\mathrm{Mo}=3.47 \times 10^{21} \mathrm{Nm}, \mathrm{Mw}=8.3$

var. $=0.0977$

$$
\begin{aligned}
\mathrm{Vr} & =3.11 \mathrm{~km} / \mathrm{sec}, 20 \mathrm{~km} \times 20 \mathrm{~km} \\
\text { Mo } & =3.30 \times 10^{21} \mathrm{Nm}, \mathrm{Mw}=8.3 \\
\text { var. } & =0.0961
\end{aligned}
$$

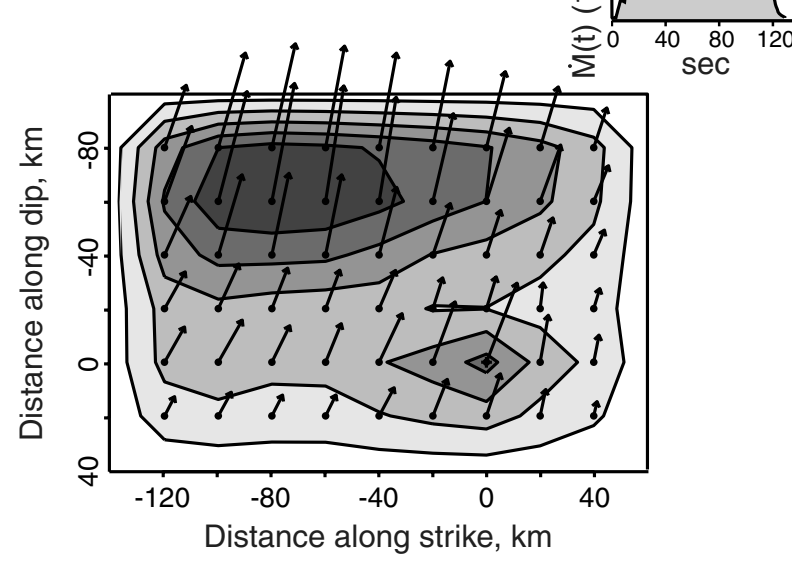

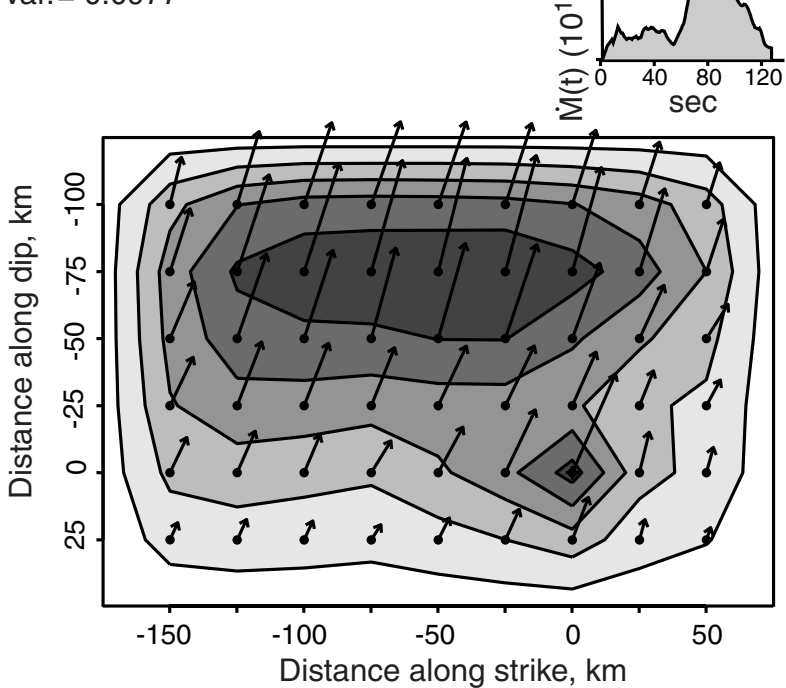

Distance along strike, $\mathrm{km}$
$\mathrm{Vr}=3.11 \mathrm{~km} / \mathrm{sec}, 30 \mathrm{~km} \times 30 \mathrm{~km}$

Mo $=3.37 \times 10^{21} \mathrm{Nm}, \mathrm{Mw}=8.3$

var. $=0.1069$

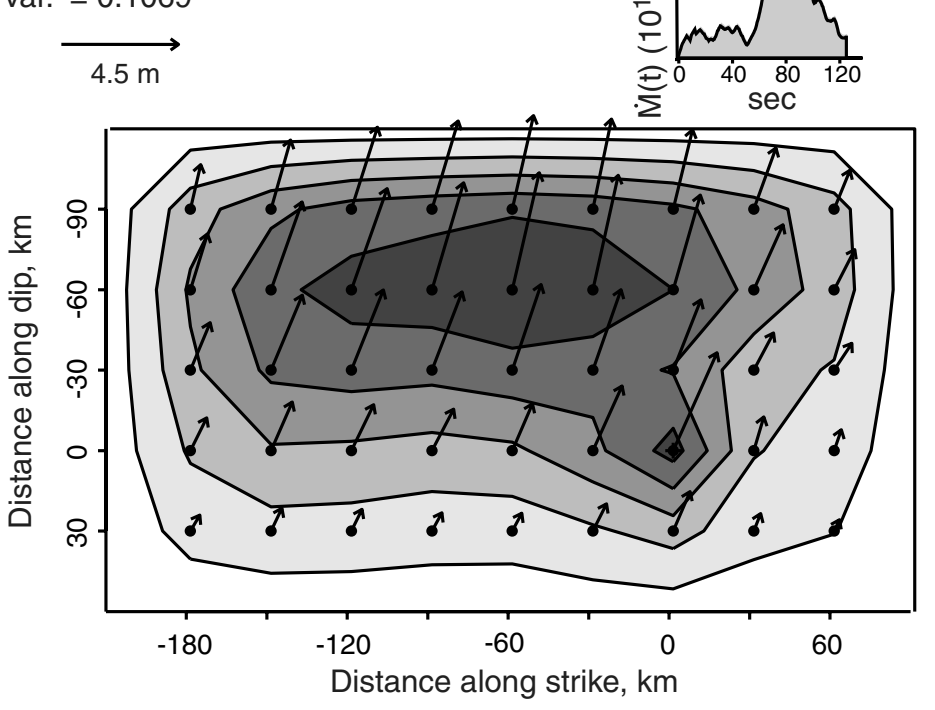

Figure 16. Finite-source models for the 2007 Peru earthquake from inversion of 50 teleseismic $P$ and $S H$ waves. Results for four different subfault grid dimensions are shown, all with the same rupture velocity of $3.11 \mathrm{~km} / \mathrm{sec}$. The focal mechanism indicates the station distribution, and has $\phi=324^{\circ}$ and $\delta=22^{\circ}$, which are the same for all solutions, and $\lambda=77^{\circ}$ is close to the average for all four solutions. The rake and total slip vector at each grid position are shown by the arrows. In every case, the subfault source-time functions are parameterized with 22 7 -sec duration triangles lagged by $3.5 \mathrm{sec}$ each, for maximum subfault rupture durations of $80.5 \mathrm{sec}$. The residual waveform mismatch variance (var.) is shown for each case. Waveform fits for the $15 \mathrm{~km} \times 15 \mathrm{~km}$ model are shown in Figure 18 . Animations of the $15 \mathrm{~km} \times$ $15 \mathrm{~km}$ case can be viewed in (E) movie 10a,b in the electronic edition of BSSA.

body waves were only weakly excited. A similar low $S H$ amplitude interval is observed for stations to the southeast. It is reasonable to infer that there was no continuous radiation in this interval and that the event is a compound earthquake doublet.

We thus consider a doublet model, for which a discrete event located near the hypocenter triggered a larger secondary event $60 \mathrm{sec}$ later. We inverted the 50 body waves for two events separated by $60 \mathrm{sec}$ in time and with hypocenters separated by $45 \mathrm{~km}$ along strike and $30 \mathrm{~km}$ along dip. We specified a normal rupture velocity of $3.11 \mathrm{~km} / \mathrm{sec}$ for both events. Event 1 is parameterized to have three 6-sec duration triangles lagged by $3 \mathrm{sec}$ each, and Event 2 had 12 6-sec duration triangles lagged by $3 \mathrm{sec}$ each, with a circular slip-pulse type rupture expanding from each hypocenter. Figure 21 shows the resulting composite slip 


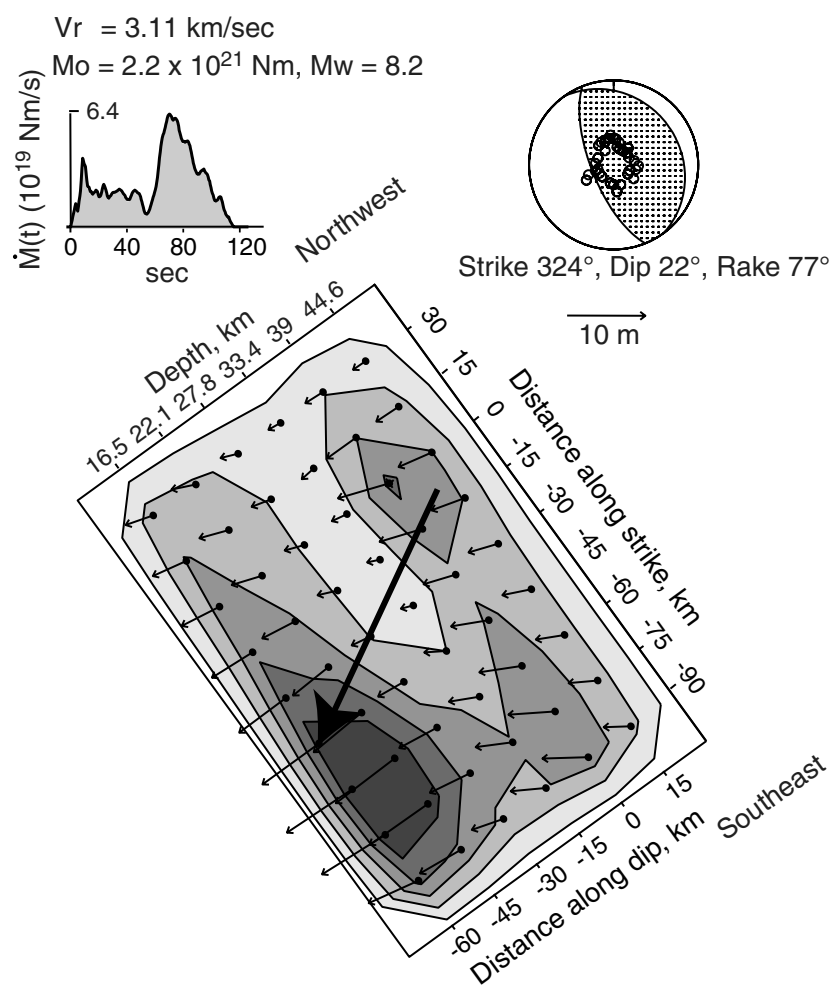

Figure 17. Comparison of the finite-source slip model for the 2007 Peru event for $V_{r}=3.11 \mathrm{~km} / \mathrm{sec}$, with $15 \mathrm{~km} \times 15 \mathrm{~km}$ subfault dimensions (from Fig. 17) with the inferred R1 unilateral rupture direction and length (arrow), in correct geographic orientation.

model. Event 1 has $M_{0} 3.5 \times 10^{20} \mathrm{Nm}$, and Event 2 has $M_{0} 1.2 \times 10^{21} \mathrm{Nm}$. (E) Waveform matches are shown in Figure S6 and the rupture animation is shown in movie 11 in the electronic edition of BSSA. This model, like the $15 \mathrm{~km} \times 15 \mathrm{~km}$ long subfault-duration model (the solution from Fig. 17 is shown on the lower right), has a patch of slip near the hypocenter and a larger patch up-dip. The first event slip model has minor up-dip slip, but this may result from the assumed 60-sec delay not being exactly correct for the second event so that some signal from the second event leaks into the slip model for the first event. While the delay between the events is $\sim 40 \mathrm{sec}$ longer than the expected Rayleigh wave arrival time from the first event, requiring an unaccounted for triggering lag, we also prefer the compound model for this event. It has a slip distribution in better general agreement with the iterative and back-projection results and a seismic moment close to long-period estimates. The long subfault-duration model accounts for the overall spatial pattern well, but the moment is overestimated and the rupture history has more irregularity than the doublet model.

\section{Discussion and Conclusions}

Ideally, finite-source rupture inversions would be performed with minimal a priori assumptions or inversion conditioning, allowing the data to directly resolve the best slip distribution model. In practice, especially when only teleseismic body waves are available, the limited resolution of source finiteness provided by teleseismic waves' narrow range of slowness values, requires imposition of at least some stabilizing constraints on the rupture modeling. $A$ priori assumption of the fault geometry is almost always necessary, and if it is viable to constrain this independently with aftershock locations or multichannel reflection profiles, at least some of the trade-off between geometry and seismic moment can be reduced. In our experience, optimizing the geometry based on measures of variance reduction in the inversion is difficult because changes in geometry produce changes in precise Green's function depths and positioning, making model-to-model comparisons difficult for multiparameter finite-source models. Thus, in all of the comparisons we present here, we hold the fault geometries constant, recognizing that details like a curved fault plane or slightly different dip may have some secondary effects on our solutions, but that these can only be resolved independently of the teleseismic data.

The constraints that we find most important to evaluate and exercise care in specifying are those imposed on how the rupture area expands and the degree of flexibility of sliding history for each subfault. The iterative inversions provide guidance on the intrinsic waveform directivity information, but the nature of the pulse-stripping method leads to instability in the precise placement of each subevent. With only a causality constraint and prescription of uniform pulse time functions, the method does allow the possibility of irregular rupture front advance, repeat sliding of subfaults, reversal of rupture front direction, and similar results, but assessing significance of the resulting detailed rupture complexity is challenging. The back-projection method provides similar, unfettered guidance on the rupture process based only on coherency of directivity effects in the seismic data, but destructive interference of signals with lapse time into the rupture as different Green's function depths or geometries are encountered may lead to erroneous apparent rupture complexity as well. The slip-pulse type models constrain the rupture expansion strongly, leading to rough slip distributions as the degree of freedom with which to match waveform details. The long-subfault slip-duration models lead to smooth final slip distributions with roughness of the rupture expansion process accommodating the waveform details. Our experience in this study is that when back projections indicate greater complexity than a slip-pulse type model, it is well worthwhile to allow for the long-subfault slip-duration possibility, so as not to overly constrain where slip is located. This also accommodates the possibility of compound events rather than smooth rupture propagation.

For the 23 June 2001 Peru earthquake, our modeling favors the notion of triggering of an $M_{\mathrm{w}} 8.4$ event by the Rayleigh waves from an $M_{\mathrm{w}} 7.5$ event (Fig. 22). Distinguishing between continuous rupture versus discrete event triggering by the Rayleigh waves is not possible, but the triggering scenario, in which the larger secondary event is naturally 

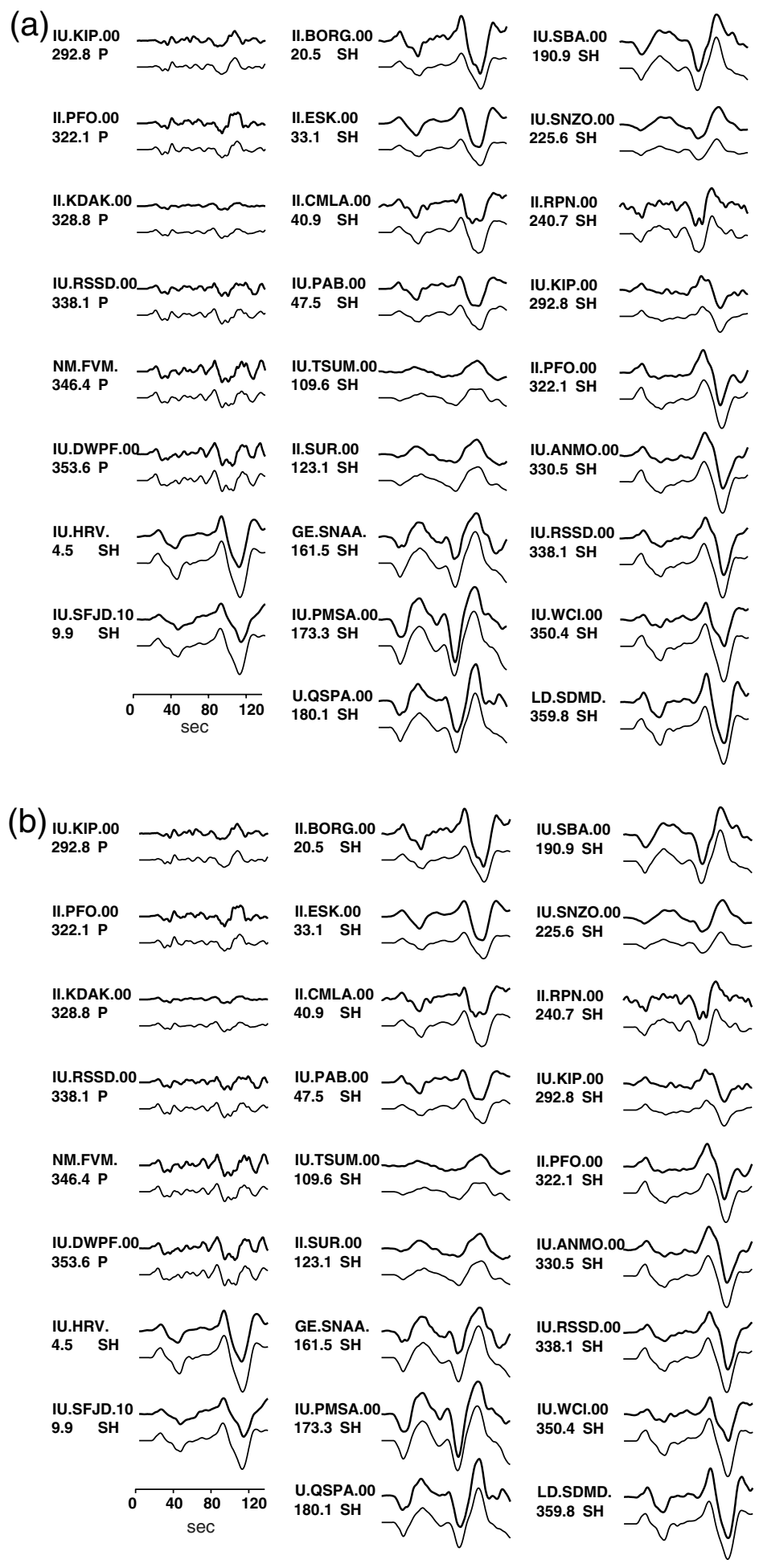

Figure 18. (a, b) Observed (upper bold lines in each pair) and synthetic (lower thin lines in each pair) teleseismic $P$ and $S H$ waves for the 2007 Peru event for the preferred model with a rupture velocity of $3.11 \mathrm{~km} / \mathrm{sec}$ and subfault source durations of $80.5 \mathrm{sec}$ (Fig. 17). The azimuth of each broadband displacement trace (filtered in the passband $0.005-0.9 \mathrm{~Hz}$ ) is indicated below the station code. Amplitudes for $S H$ waves are on $1 / 5$ scale relative to $P$ waves. 


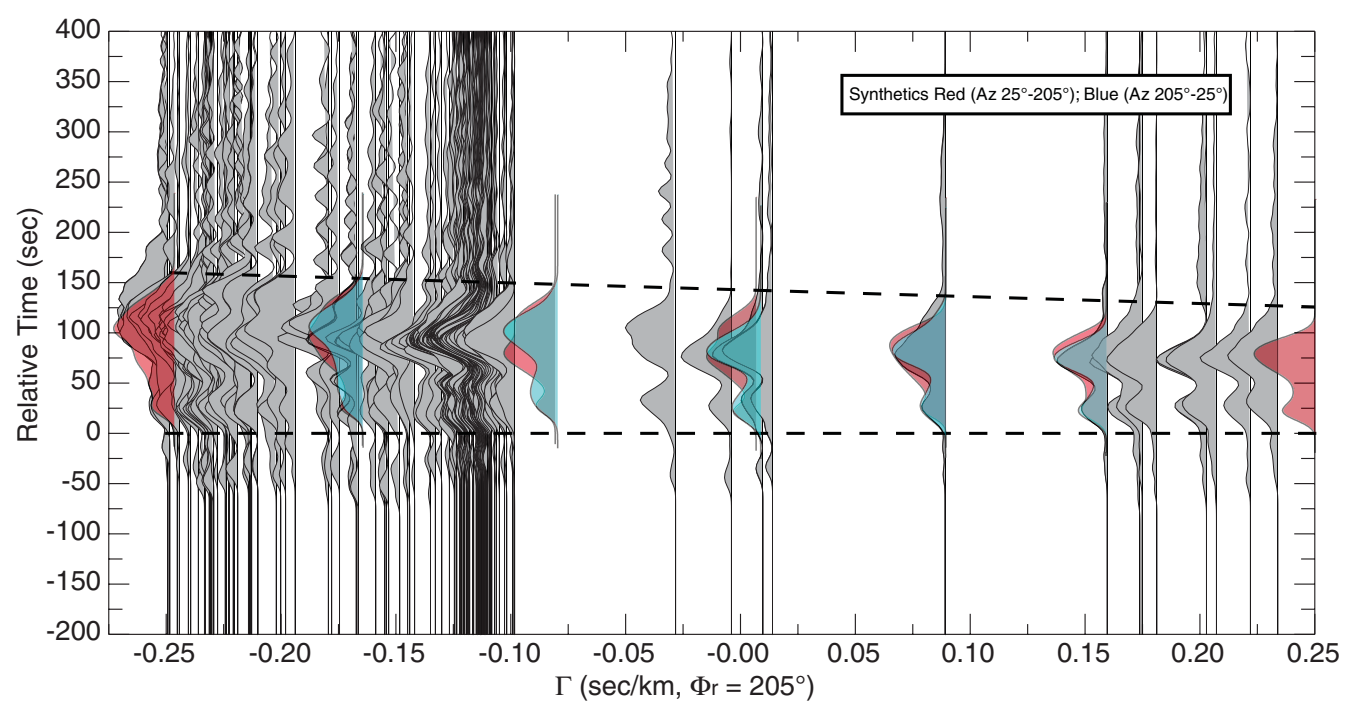

Figure 19. Comparison of observed and predicted R1 effective source-time functions for the 2007 Peru event for the rupture model shown in Figure 17. The red and blue traces are synthetics distinguished by azimuth relative to the average rupture direction of $205^{\circ}$ (red traces are azimuths to the southeast range; blue are azimuths to the northwest). Both data and synthetics have been convolved with a Gaussian filter with averaging width 0.1 . The model matches the overall variation in duration and general aspects of the complexity of the R1 observations.

expected to spread radially outward on the fault, provides a natural explanation for how late rupture occurs between the two hypocenters. This is precluded by the slip-pulse type models, and while the long-subfault slip-duration models allow it, they end up with much more complex overall rupture histories because there is no kinematic constraint on the late rupture prior to the healing front sweeping through. By directly comparing back projections of the $P$ waves used in the finite-source inversions with back projection of the synthetics for each basic model type, we can ascertain the consistency of the finite-source models. Side-by-side animations

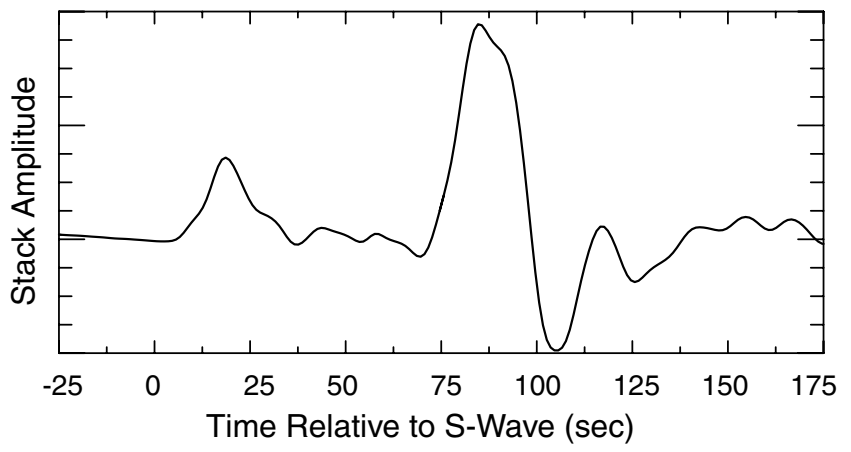

Figure 20. Linear stack of aligned $S H$ waves recorded by the EarthScope Transportable Array for the 2007 Peru earthquake. The data were deconvolved by the instrument responses to restitute ground displacement, and then aligned on the first arrival. Only waveforms at distances less than $65^{\circ}$ were included in the stack to avoid contamination by $S c S$ reflections. The two-pulse nature of the ground motions is clearly evident, with there being negligible arrival of $S H$-energy in the intervening $40 \mathrm{sec}$. The stations are located at azimuths along the trench strike, and hence are in a stable portion of the $S H$ wave radiation pattern. for the 2001 event are provided in (E) movie 12 in the electronic edition of BSSA. The animations clearly demonstrate the failure of the slip-pulse model to match the late slip on the fault near the hypocenter, which is well accounted for by the long slip duration and triggered doublet scenarios. The triggered doublet and long slip duration models are also both more consistent with the GPS and InSAR based models than the slip-pulse models (compare Fig. 2a and Fig. 22). It does appear that the larger event in the doublet has a lower overall rupture velocity than the triggering event, which may reflect the fact that most of the slip occurs at shallower depth on the fault plane, extending up into the sedimentary wedge. Dynamic triggering of remote seismicity by propagating surface waves has been well-documented for the 1992 Landers and 2002 Denali earthquakes (e.g., Hill et al., 1993; Gomberg et al., 2004), along with other events (e.g., Velasco et al., 2008), but demonstration that great megathrust earthquakes may be the result of a dynamically triggered cascade has not been possible in general and will continue to prove challenging.

Triggering of a large secondary event is also our preferred explanation for the 15 August 2007 Peru earthquake (Fig. 22), but in this case the delay of the triggered rupture relative to the passage of the initial event rupture front and seismic waves makes the case more compelling. The alternative is a very slow rupture velocity, comparable to that of very shallow tsunami earthquakes; there is no independent evidence favoring slow rupture for this event (Sladen et al., 2010). The compound nature of the event, with an $M_{\mathrm{w}} \sim 7.8$ event triggering an $M_{\mathrm{w}} \sim 8.0$ event $\sim 60 \mathrm{sec}$ later and $\sim 55 \mathrm{~km}$ away, results in very compact overall source dimensions for the composite event, despite there being little overlap in their slip zones. 

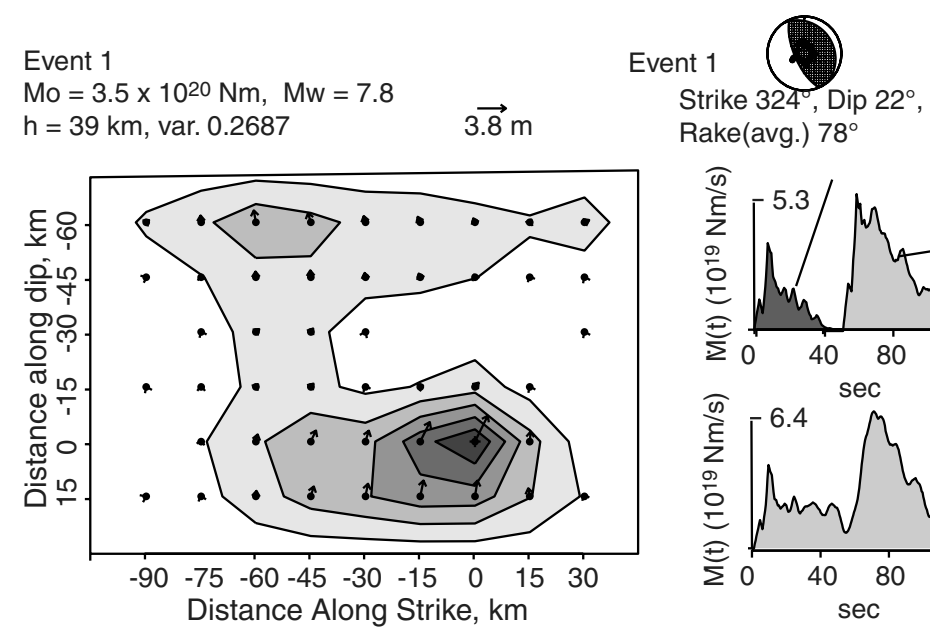

Event 2 Rake(avg.) $78^{\circ}$

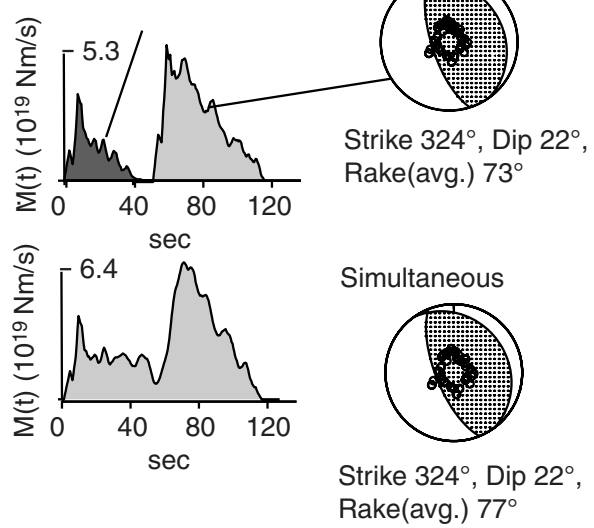

Event 2

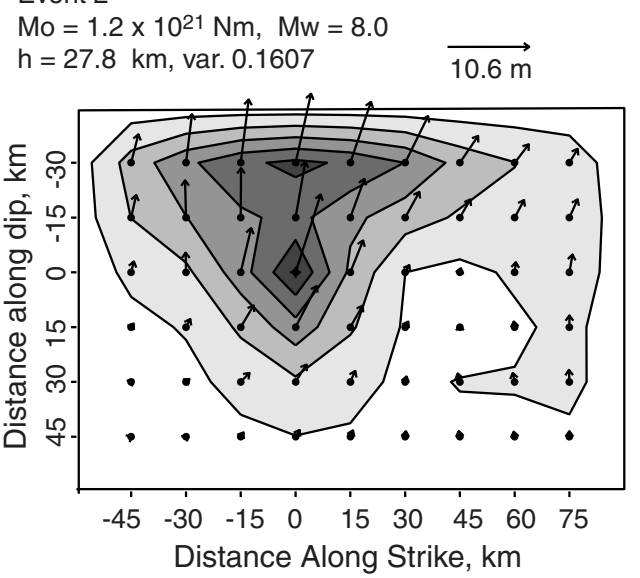

Simultaneous

$\mathrm{Mo}=2.1 \times 10^{21} \mathrm{Nm}, \mathrm{Mw}=8.2$

$\mathrm{h}=39 \mathrm{~km}$, var. $0.1177 \quad \overrightarrow{10 \mathrm{~m}}$

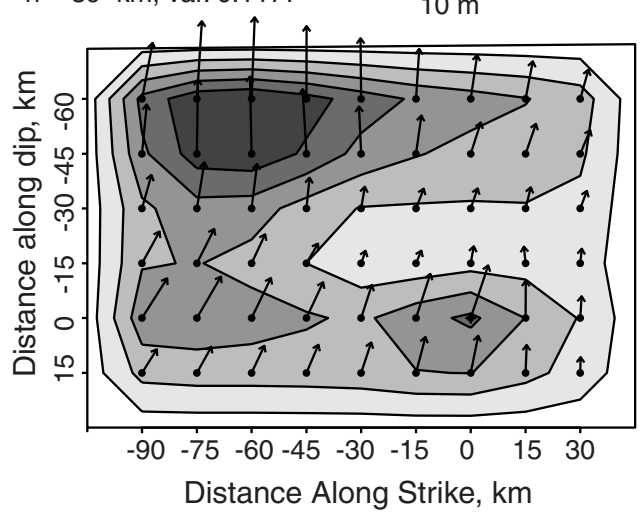

Figure 21. Two-event composite rupture model for the 2007 Peru earthquake. The event was treated like a double earthquake, with events 1 and 2 separated by $60 \mathrm{sec}$ in time and with hypocenters separated by $45 \mathrm{~km}$ along strike and $30 \mathrm{~km}$ along dip. Fifty teleseismic $P$ and $\mathrm{SH}$ waves were inverted for the slip functions of each event, which are shown on the left. The combined source-time function of the double event (top right) is compared with the simultaneous inversion result from Figure 17 on the right. (E) Waveform fits for the composite model are shown in Figure S6 and an animation of the slip model is shown in movie 11a,b in the electronic edition of BSSA.

The cause of the 60-sec delay is unclear, and various nucleation processes have been considered (Sladen et al., 2010). Side-by-side animations of back projections of the $P$-wave data used in the finite-source inversions and corresponding synthetics for each model type for the 2007 event are provided in (E) movie 13 in the electronic edition of BSSA. All of the major features of the data are matched by each model type in this case, mainly as a result of the very compact source dimensions. Overall, the back projection and iterative deconvolution results certainly motivate the consideration of longsubfault slip-duration or compound event models and the likely inadequacy of slip-pulse type models even with low rupture velocity. This is reinforced by the improved agreement of the seismic models with GPS and InSAR inversions, with slip occurring both northwest and southwest (up-dip) of the Paracas peninsula (compare Fig. 2c and Fig. 22). The concentration of slip up-dip to the southwest still provides good explanation for the strong tsunami run-ups observed south of the peninsula, as was the case for the slip-pulse model of Ji and Zeng (2007).

While this article indicates that at least some great earthquakes rupture in a fashion that cannot be adequately modeled by routine slip-pulse inversion methods that are being widely used, the final results obtained with long-subfault slip-duration or compound earthquake representations do eliminate most of the discrepancies noted relative to geodetic inversions. Thus, there is no clear need to invoke a seismic blind spot for significant coseismic slip components for these great Peru earthquakes, as has ultimately proved to be true even for the great 2004 Sumatra events (e.g., Chlieh et al., 2007). There is also no evidence for anomalously slow rupture velocities for these events. It is viable to produce rapid, reliable slip models using early-arriving teleseismic body waves with a combination of back projection, iterative deconvolution, slip-pulse, and/or long-subfault slip-duration models that can reliably guide effective earthquake response, 
(a)

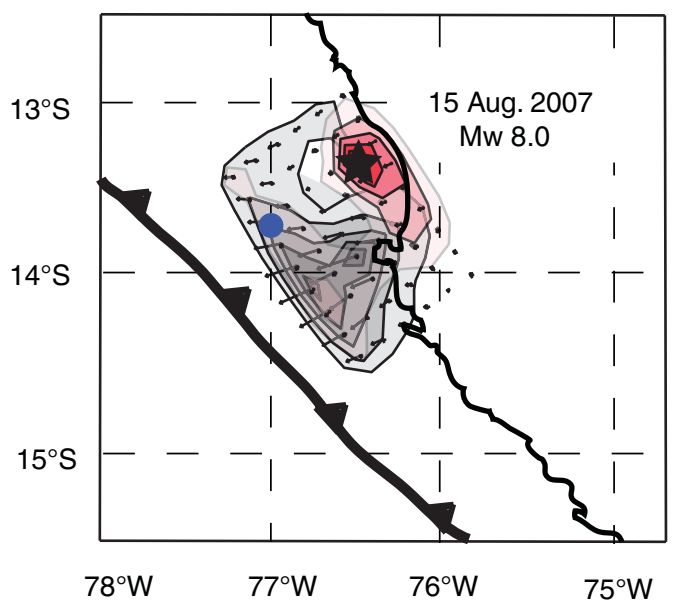

(b)

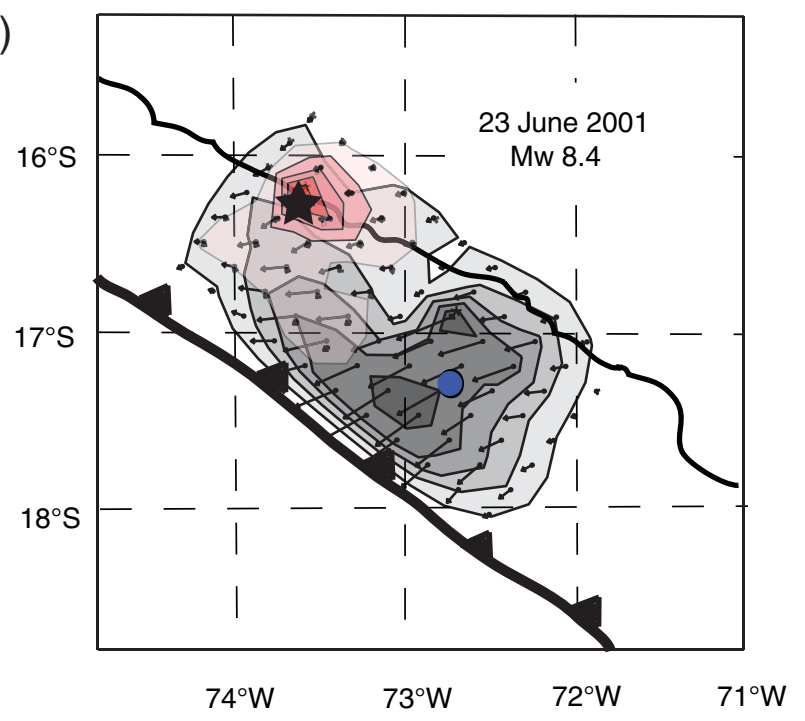

Figure 22. Maps showing the slip distribution for the preferred doublet event models for (a) the 2007 and (b) 2001 Peru earthquakes. The slip region for the first event in each pair is indicated by the red tones. The stars indicate the USGS epicenters and the blue circles indicate the CMT centroid locations. (Comparisons of back projections of the subset of inverted $P$ waves and all three types of rupture model for each event are shown as animations in (E) movies 12 and 13 in the electronic edition of BSSA.)

tsunami-generation assessment, and joint studies with geodetic data.

\section{Data and Resources}

All seismic data used in this article were freely and openly available from the IRIS data center. The software used for inverting the signals for finite-source models was freely and openly available from M. Kikuchi and H. Kanamori (www.eri.u-tokyo.ac.jp/ETAL/KIKUCHI/).

\section{Acknowledgments}

We thank the Global Seismic Network, Federation of Digital Seismic Networks, EarthScope USArray operators, and the IRIS Data Management
System for providing access to the bountiful, well-calibrated broadband seismic recordings used in this article. We have benefited from discussions with Chen Ji concerning parameterizations for finite-source inversions. We thank Gavin Hayes for a review and two anonymous reviewers for their helpful comments. Anthony Sladen kindly provided a preprint in advance of publication. This article is supported by NSF grants EAR0453884 and EAR0635570 (TL) and USGS Award Number 05HQGR0174 (CJA).

\section{References}

Ammon, C. J., C. Ji, H.-K. Thio, D. Robinson, S. Ni, V. Hjorleifsdottir, H. Kanamori, T. Lay, S. Das, D. Helmberger, G. Ichinose, J. Polet, and D. Wald (2005). Rupture process of the great 2004 SumatraAndaman earthquake, Science 308, 1133-1139.

Ammon, C. J., H. Kanamori, and T. Lay (2008). A great earthquake doublet and seismic stress transfer cycles in the Central Kuril Islands, Nature 451, 561-565.

Ammon, C. J., A. A. Velasco, and T. Lay (2006). Rapid determination of first-order rupture characteristics for large earthquakes using surface waves: The 2004 Sumatra-Andaman earthquake, Geophys. Res. Lett. 33, L14314, doi 10.1029/2006GL026303.

Anderson, B. E., T. J. Ulrich, M. Griffa, P.-Y. Le Bas, M. Scalerandi, A. Gliozzi, and P. A. Johnson (2009). Experimentally identifying masked sources applying time reversal with the selective source reduction method, J Appl Phys. 105, no. 8, 083506, doi 10.1063/1.3079517.

Biggs, J., D. P. Robinson, and T. H. Dixon (2009). The 2007 Pisco, Peru, earthquake ( $M$ 8.0): Seismology and geodesy, Geophys. J. Int. 176, 657-669.

Bilek, S. L., and L. J. Ruff (2002). Analysis of the 23 June $2001 M_{\mathrm{w}}=8.4$ Peru underthrusting earthquake and its aftershocks, Geophys. Res. Lett. 29, no. 20, 1960, doi 10.1029/2002GL015543.

Boschi, L., and G. Ekström (2002). New images of the Earth's upper mantle from measurements of surface-wave phase velocity anomalies, J. Geophys. Res. 107, doi 10.1029/2000JB000059.

Chlieh, M., J.-P. Avouac, V. Hjorleifsdottir, T-R. A. Song, J. Chan, K. Sieh, A. Sladen, H. Herbert, L. Prawirodirdjo, Y. Bock, and J. Galetzka (2007). Coseismic slip and afterslip of the great $\left(M_{\mathrm{w}} 9.15\right)$ Sumatra-Andaman earthquake of 2004, Bull. Seismol. Soc. Am. 97, no. 1A, pp. S152-S173, doi 10.1785/0120050631.

Das, S., and B. V. Kostrov (1990). Inversion for seismic slip rate history and distribution with stabilizing constraints: Application to the 1986 Andreanof Islands earthquakes, J. Geophys. Res. 95, 6899-6913.

Dziewonski, A. M., and D. L. Anderson (1981). Preliminary reference Earth model, Phys. Earth Planet. In. 25, 297-356.

Ekström, G. (2009). Global CMT web page, http://www.globalcmt.org/ (last accessed September 1, 2009).

Eshelby, J. D. (1957). The determination of the elastic field of an ellipsoidal inclusion, and related problems, Proc. R. Soc. London, Ser. A 241, 376-396.

Fritz, H. M., N. Kalligeris, J. C. Borrero, P. Broncano, and E. Ortega (2008). The 15 August 2007 Peru tsunami runup observations and modeling, Geophys. Res. Lett. 35, L10604, doi 10.1029/2008GL033494.

Giovanni, M. K., S. L. Beck, and L. Wagner (2002). The June 23, 2001 Peru earthquake and the southern Peru subduction zone, Geophys. Res. Lett. 29, no. 21, 2018, doi 10.1029/2002GL015774.

Gomberg, J., P. Bodin, K. Larson, and H. Dragert (2004). Earthquake nucleation by transient deformations caused by the $M=7.9$ Denali, Alaska, earthquake, Nature 427, 621-624.

Hartzell, S. H., and T. H. Heaton (1983). Inversion of strong ground motion and teleseismic waveform data for the fault rupture history of the 1979 Imperial Valley, California, earthquake, Bull. Seismol. Soc. Am. 73, $1553-1583$.

Haskell, N. A. (1964). Total energy and spectral density of elastic wave radiation form propagating faults, Bull. Seismol. Soc. Am. B, 1811-1844.

Hayes, G. P., and D. J. Wald (2009). Developing framework to constrain the geometry of the seismic rupture plane on subduction interfaces 
a priori-A probabilistic approach, Geophys. J. Int. 176, 951-964, doi 10.1111/j.1365-246X.2008.04035.x.

Hill, D. P., P. A. Reasenberg, A. Michael, W. J. Arabaz, G. Beroza, D. Brumbaugh, J. N. Brune, R. Castro, S. Davis, D. dePolo, W. L. Ellsworth, J. Gomberg, S. Harmsen, L. House, S. M. Jackson, M. J. S. Johnston, L. Jones, R. Keller, S. Malone, L. Munguia, S. Nava, J. C. Pechmann, A. Sanford, R. W. Simpson, R. B. Smith, M. Stark, M. Stickney, A. Vidal, S. Walter, V. Wong, and J. Zollweg (1993). Remote seismicity triggered by the $M 7.5$ Landers, California earthquake of June 28, 1992, Science 260, 1617-1623.

Ishii, M., P. M. Shearer, H. Houston, and J. E. Vidale (2005). Extent, duration and speed of the 2004 Sumatra-Andaman earthquake imaged by the Hi-net array, Nature 435, 933-936.

Ji, C., and Y. Zeng (2007). Preliminary result of the Aug. 15, $2007 M_{\mathrm{w}} 8.0$ coast of central Peru earthquake, http://earthquake.usgs.gov/eqcenter/ eqinthenews/2007/us2007gbcv/finite_fault.php (last accessed September 1, 2009).

Ji, C., D. Wald, and D. Helmberger (2002). Source description of the 1999 Hector Mine, California, earthquake, Part I: Wavelet domain inversion theory and resolution analysis, Bull. Seismol. Soc. Am. 92, 1192-1207.

Kanamori, H., and L. Rivera (2008). Source inversion of $W$-phase: Speeding up seismic tsunami warning, Geophys. J. Int. 175, 222-238.

Kawakatsu, H., and J.-P. Montagner (2008). Time-reversal seismic-source imaging and moment-tensor inversion, Geophys. J. Int. 175, no. 2, 686-688.

Kikuchi, M., and Y. Yamanaka (2001). Special event page-2001/06/23 Near coast of Peru (M 7.9)-Earthquake Information Center Tokyo Japan, http://wwweic.eri.u-tokyo.ac.jp/topics/200106232033/ (last accessed September 1, 2009).

Knopoff, L., and F. Gilbert (1959). Radiation from a strike slip fault, Bull. Seismol. Soc. Am. 49, 163-178.

Konca, A. O., J.-P. Avouac, A. Sladen, A. J. Meltner, K. Sieh, P. Fang, Z. Li, J. Galetzka, J. Genrich, M. Chlieh, D. H. Natawidjaja, Y. Bock, E. J. Fielding, C. Ji, and D. V. Helmberger (2008). Partial rupture of a locked path of the Sumatra megthrust during the 2007 earthquake sequence, Nature 456, 631-635, doi 10.1038/nature07572.

Konca, A. O., V. Hjorleifsdottir, T. A. Song, J. Avouac, D. V. Helmberger, C. Ji, K. Sieh, R. Briggs, and A. Meltzner (2007). Rupture kinematics of the $2005 M_{\mathrm{w}} 8.6$ Nias-Simeulue earthquake from the joint inversion of seismic and geodetic data, Bull. Seismol. Soc. Am. 97, S307-S322, doi 10.1785/0120050632.

Krüger, F., and M. Ohrnberger (2005). Tracking the rupture of the $M_{\mathrm{w}}=9.3$ Sumatra earthquake over $1,150 \mathrm{~km}$ at teleseismic distance, Nature $\mathbf{4 3 5}$, 937-939.

Larmat, C., J.-P. Montagner, M. Fink, Y. Capdeville, A. Tourin, and E. Clévédé (2006). Time-reversal imaging of seismic sources and application to the great Sumatra earthquake, Geophys. Res. Lett. 33, L19312, doi 10.1029/2006GL026336.

Lay, T., H. Kanamori, C. J. Ammon, A. R. Hutko, K. Furlong, and L. Rivera (2009). The 2006-2007 Kuril Islands great earthquake sequence, J. Geophys. Res. 114, B11308, doi 10.1029/2008JB006280.

Motagh, M., R. Wang, T. R. Walter, R. Bürgmann, E. Fielding, J. Anderssohn, and J. Zschau (2008). Coseismic slip model of the 2007 August Pisco earthquake (Peru) as constrained by wide swath radar observations, Geophys. J. Int. 174, 842-848.

Okamoto, T., and H. Takenaka (2009). Waveform inversion for slip distribution of the 2006 Java tsunami earthquake by using 2.5D finitedifference Green's function, Earth Planets Space 61, e17-e20.

Pritchard, M. E., and E. J. Fielding (2008). A study of the 2006 and 2007 earthquake sequence of Pisco, Peru, with InSAR and teleseismic data, Geophys. Res. Lett. 35, L09308, doi 10.1029/2008GL033374.

Pritchard, M. E., E. O. Norabuena, C. Ji, R. Boroschek, D. Comte, M. Simons, T. H. Dixon, and P. A. Rosen (2007). Geodetic, teleseis- mic, and strong motion constraints on slip from recent southern Peru subduction zone earthquakes, J. Geophys. Res. 112, B03307, doi 10.1029/2006JB004294.

Robinson, D. P., S. Das, and A. B. Watts (2006). Earthquake rupture stalled by a subducting fracture zone, Science 312, 1203-1205.

Salichon, J., B. Delouis, P. Lundgren, D. Giardini, M. Costantini, and P. Rosen (2003). Joint inversion of broadband teleseismic and interferometric synthetic aperture radar (InSAR) data for the slip history of the $M_{\mathrm{w}}=7.7$ Nazca ridge (Peru) earthquake of 12 November 1996, J. Geophys. Res. 108, 2085, doi 10.1029/2001JB000913.

Savage, J. C. (1966). Radiation from a realistic model of faulting, Bull. Seismol. Soc. Am. 56, 577-592.

Sladen, A., H. Tavera, M. Simons, J. P. Avouac, A. O. Konca, H. Perfettini, L. Audin, E. J. Fielding, F. Ortega, and R. Cavagnoud (2010). Source model of the $2007 M_{\mathrm{w}} 8.0$ Pisco, Peru earthquake-Implications for seismogenic behavior of subduction megathrusts, J. Geophys. Res., 115, B02405, doi 10.1029/2009JB006429.

Vallée, M. (2007). Séisme du Pérou, http://geoazur.oca.eu/spip.php? article107 (last accessed September 1, 2009).

Velasco, A. A., S. Hernandez, T. Parsons, and K. Pankow (2008). Global ubiquity of dynamic earthquake triggering, Nature Geoscience 1, 375-379.

Walker, K. T., and P. M. Shearer (2009). Illuminating the near-sonic rupture velocities of the intracontinental Kokoxili $M_{\mathrm{w}} 7.8$ and Denali $M_{\mathrm{w}} 7.9$ strike-slip earthquakes with global P-wave back projection imaging, J. Geophys. Res. 114, B02304, doi 10.1029/2008JB005738.

Xu, Y., K. D. Koper, O. Sufri, L. Zhu, and A. R. Hutko (2009). Rupture imaging of the $M_{\mathrm{w}} 7.912$ May 2008 Wenchuan earthquake from back projection of teleseismic $P$ waves, Geochem. Geophys. Geosys. 10, Q04006, doi 10.1029/2008GC002335 (last accessed September 1, 2009).

Yagi, Y. (2007). 2007 August 16 off Peru giant earthquake, Tsukuba University, http://www.geo.tsukuba.ac.jp/press_HP/yagi/EQ/20070816/ (in Japanese; last accessed September 1, 2009).

Yamanaka, Y. (2007). NGY seismological note $\mathrm{N}^{\circ} 3$ : August 15 Peru earthquake, http://www.seis.nagoya-u.ac.jp/sanchu/Seismo_Note/2007/ NGY3.html (in Japanese; last accessed September 1, 2009).

Earth and Planetary Sciences Department

University of California

1156 High Street

Santa Cruz, California 95064

thorne@pmc.ucsc.edu

(T.L.)

Department of Geosciences

The Pennsylvania State University

University Park, Pennsylvania

(C.J.A.)

United States Geological Survey

Golden, Colorado

(A.R.H.)

Seismological Laboratory

California Institute of Technology

Pasadena, California

(H.K.)

Manuscript received 2 September 2009 